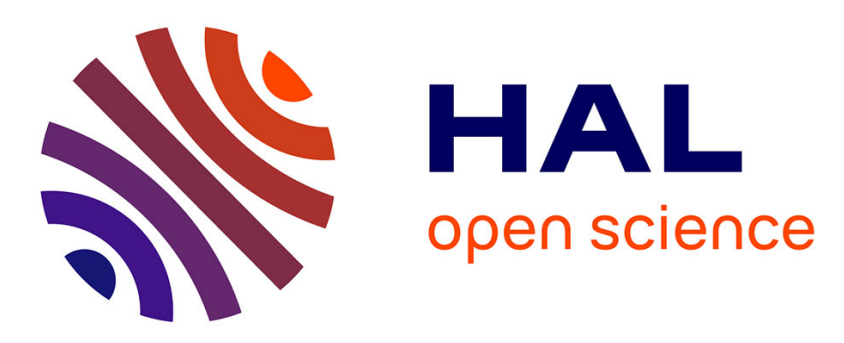

\title{
West African Monsoon water cycle: 1. A hybrid water budget data set
}

Remi Meynadier, Olivier Bock, F. Guichard, A. Boone, P. Roucou, J.-L. Redelsperger

\section{- To cite this version:}

Remi Meynadier, Olivier Bock, F. Guichard, A. Boone, P. Roucou, et al.. West African Monsoon water cycle: 1. A hybrid water budget data set. Journal of Geophysical Research: Atmospheres, 2010, 115 (D19), pp.D19106. 10.1029/2010JD013917 . hal-00477346

\section{HAL Id: hal-00477346 \\ https://hal.science/hal-00477346}

Submitted on 25 Feb 2016

HAL is a multi-disciplinary open access archive for the deposit and dissemination of scientific research documents, whether they are published or not. The documents may come from teaching and research institutions in France or abroad, or from public or private research centers.
L'archive ouverte pluridisciplinaire HAL, est destinée au dépôt et à la diffusion de documents scientifiques de niveau recherche, publiés ou non, émanant des établissements d'enseignement et de recherche français ou étrangers, des laboratoires publics ou privés. 


\title{
West African Monsoon water cycle:
}

\section{A hybrid water budget data set}

\author{
R. Meynadier, ${ }^{1}$ O. Bock, ${ }^{1,2}$ F. Guichard, ${ }^{3}$ A. Boone, ${ }^{3}$ P. Roucou, ${ }^{4}$ and J.-L. Redelsperger ${ }^{3}$
}

Received 22 January 2010; revised 22 April 2010; accepted 26 April 2010; published 1 October 2010.

[1] This study investigates the West African Monsoon water cycle with the help of a new hybrid water budget data set developed within the framework of the African Monsoon Multidisciplinary Analyses. Surface water and energy fluxes are estimated from an ensemble of land surface model simulations forced with elaborate precipitation and radiation products derived from satellite observations, while precipitable water tendencies are estimated from numerical weather prediction analyses. Vertically integrated atmospheric moisture flux convergence is estimated as a residual. This approach provides an advanced, comprehensive atmospheric water budget, including evapotranspiration, rainfall, and atmospheric moisture flux convergence, together with other surface fluxes such as runoff and net radiation. The annual mean and the seasonal cycle of the atmospheric water budget are presented and the couplings between budget terms are discussed for three climatologically distinct latitudinal bands between $6^{\circ} \mathrm{N}$ and $20^{\circ} \mathrm{N}$. West Africa is shown to be alternatively a net source and sink region of atmospheric moisture, depending on the season (a source during the dry season and a sink during the wet season). Several limiting and controlling factors of the regional water cycle are highlighted, suggesting strong sensitivity to atmospheric dynamics and surface radiation. Some insight is also given into the underlying smaller-scale processes. The relationship between evapotranspiration and precipitation is shown to be very different between the Sahel and the regions more to the south and partly controlled by net surface radiation. Strong correlations are found between precipitation and moisture flux convergence over the whole region from daily to interannual time scales. Causality is also established between monthly mean anomalies. Hence, precipitation anomalies are preceded by moisture flux convergence anomalies and followed by moisture flux divergence and evapotranspiration anomalies. The results are discussed in comparison to other studies.

Citation: Meynadier, R., O. Bock, F. Guichard, A. Boone, P. Roucou, and J.-L. Redelsperger (2010), West African Monsoon water cycle: 1. A hybrid water budget data set, J. Geophys. Res., 115, D19106, doi:10.1029/2010JD013917.

\section{Introduction}

[2] The water cycle is a major component of the global climate system [Peixoto and Oort, 1983]. Understanding the water cycle of the West African Monsoon (WAM) system and its variability in the context of climate change is a major objective of African Monsoon Multidisciplinary Analyses (AMMA [Redelsperger et al., 2006]). Rainfall is indeed of crucial importance in vulnerable regions such as the Sahel which experienced severe droughts since the 1970s and increased interannual variability in observed rainfall [Nicholson, 1981; Le Barbé et al., 2002]. Seasonal rainfall over the Sahel is mostly contributed by mesoscale convective systems (MCSs). In terms of water budget, about $90 \%$ of

\footnotetext{
${ }^{1}$ LATMOS, Université Pierre et Marie Curie, CNRS, Paris, France.

${ }^{2}$ Also at LAREG, IGN, Marne-la-Vallee, France.

${ }^{3}$ GAME-CNRM, CNRS, Météo-France, Toulouse, France.

${ }^{4} \mathrm{CRC}$, Université de Bourgogne, CNRS, Dijon, France.
}

Copyright 2010 by the American Geophysical Union. 0148-0227/10/2010JD013917 seasonal rainfall is produced by a few $(\sim 12 \%)$ large organized MCSs [Lebel et al., 1997; Mathon et al., 2002]. Numerous synoptic meteorological factors modulate the occurrence and variability of such organized MCSs [Barnes and Sieckman, 1984; Laing and Fritsch, 1993; Diedhiou et al., 1999; Redelsperger et al., 2002; Diongue et al., 2002; Fink and Reiner, 2003]. At intraseasonal scale, convective activity is modulated by large-scale dynamics and global-scale disturbances [Sultan et al., 2003; Matthews, 2004; Mounier et al., 2008], and at interannual scale to multidecadal time scales, links have been established between rainfall variability and upper air circulation [Kidson, 1977; Lamb, 1983; Fontaine et al., 1995; Long et al., 2000; Grist and Nicholson, 2001]. In addition, the significance of land-atmosphere interactions [Charney, 1975; Taylor and Lebel, 1998; Zeng et al., 1999; Douville et al., 2001; Koster et al., 2004; Taylor, 2008], and ocean-atmosphere interactions has been identified across a range of space and time scales [Rowell et al., 1995; Janicot et al., 1998; Vizy and Cook, 2001; Giannini et al., 2003]. 
[3] Water budgets and continental water recycling computations are two efficient diagnostics to highlight the strength of processes which participate to the water cycle. Precipitation over a land region is derived from two sources: (1) water vapor advected into the region by atmospheric circulation and (2) water vapor supplied by local evapotranspiration from the land surface [Brubaker et al., 1993]. The efficiency of both mechanisms is highly scale dependent [Trenberth, 1999] and the computation of budgets and recycling indexes is subject to various error sources [Trenberth and Guillemot, 1995; Mo and Higgins, 1996; Rasmusson and Mo, 1996].

[4] Studies of the West African water cycle are few. Cadet and Nnoli [1987] investigated water transport over West Africa and the Atlantic Ocean for the summer 1979 using winds from a European Centre for Medium-Range Weather Forecasts (ECMWF) analysis and humidity fields from satellite-based retrievals. They estimated water budgets and investigated the respective roles of evaporation over the Gulf of Guinea and evapotranspiration north to the Guinean coast. They concluded that moisture from the ocean was a major source for rainfall over West Africa but emphasized also the importance of moisture recycling. Brubaker et al. [1993] used a 10 year gridded aerological data set [Oort, 1983] and a precipitation data set from the World Monthly Surface Station Climatology. They found that, in July and September, West Africa is source of moisture and estimated a continental recycling to around $40 \%$ (representative of an area of $2 \cdot 10^{6} \mathrm{~km}^{2}$ ). Gong and Eltahir [1996] used a 3 years subset of ECMWF analysis and precipitation atlas climatology [Shea, 1986]. They quantified the contribution from the tropical Atlantic Ocean to $23 \%$ and local continental recycling to $27 \%$ (over areas of $\sim 3 \cdot 10^{6} \mathrm{~km}^{2}$ ), which is smaller than the estimates of Brubaker [1993]. Nicholson et al. [1997] used various observational data sets as forcings to a surface water balance model which simulates monthly mean water budget terms. Their results suggest that evapotranspiration represents a significant fraction of the total water budget both at annual and monthly mean scales, and that interannual variability in evapotranspiration and rainfall are almost equal, especially over the Sahel. Fontaine et al. [2003], using NCEP-NCAR Reanalysis, identified the Sudanian and Guinean regions as sink areas in JAS and emphasized the weight of moisture advection in the interannual variability of rainfall. Their results are consistent with those of Cadet and Nnoli [1987] and Gong and Eltahir [1996], but in contrast with those of Brubaker et al. [1993], Nicholson et al. [1997], and also more recently Nieto et al. [2006], who support the idea that recycling represents a significant contribution to the annual mean and interannual variability.

[5] There is clearly a lack of consensus among these studies. Beyond differences which occur when considering distinct time periods and/or regions, uncertainties affecting each of the various data sets used in the past over West Africa are key factors. Indeed, a major limitation in this region has been the scarcity of observations and the too approximate parameterizations of physical processes used in models. The present work is intended to take benefit from the unprecedented observing and modeling effort conducted over West Africa in the framework of AMMA. A new water budget data set is computed on the basis of an ensemble of land surface models (LSMs), satellite precipitation estimates, and numerical weather prediction (NWP) analyses. One of the budget terms is directly validated with GPS precipitable water vapor observations [Bock et al., 2008].

[6] The main objectives of this study are to quantify the annual mean water budget and its seasonal cycle, and to revisit the interannual variability and correlations in water budget terms at regional scale. Insight is also given into smaller scales, closer to the fine scales at which monsoonal rainfall processes operate. The present paper focused on the hybrid water budget data set. A companion paper assesses the water cycle as represented in various NWP models in comparison to the hybrid data set [Meynadier et al., 2010]. The organization of this paper is the following. Section 2 (and Appendix A) introduces the hybrid data set. In section 3, the annual mean, seasonal cycle and submonthly variability of the atmospheric water budget are investigated. Section 4 analyses the interannual variability and interrelations of the water budget terms. Section 5 discussed the present results in comparison to other studies. Section 6 concludes and introduces part II of the study.

\section{Data and Methodology}

[7] The vertically integrated atmospheric water budget is governed by the following equation relating four terms [Peixoto and Oort, 1983]:

$$
\mathrm{dPW}=E-P-\mathrm{MFD},
$$

where $\mathrm{dPW}$ is a short notation for the time derivative of precipitable water vapor (PWV), i.e., $\mathrm{dPW}=\partial P W V / \partial t, E$ is evapotranspiration over the continental surface (or evaporation over the ocean), $P$ is the precipitation at the surface, and MFD is the vertically integrated moisture flux divergence. Sometimes we refer also to MFC $=-\mathrm{MFD}$, which is the moisture flux convergence. In the present work, the $E$ and $P$ estimates are provided by LSM simulations and satellite precipitation estimates, respectively, while PWV tendency is provided by NWP model analyses. The MFD estimate is then derived as a residual from the budget equation:

$$
\mathrm{MFD}_{\text {hyb }}=E_{\mathrm{LSM}}-P_{\text {sat }}-\mathrm{dPW}_{\mathrm{NWP}},
$$

The method is so-called hybrid because it combines several elaborate products. One important aspect for investigating the links between the processes involved in this water budget is that the budget is closed. In the present case, this requirement is verified by construction, at all scales. It does not preclude errors in each process though. The hybrid MFD is actually computed from daily mean $E$ and $P$ estimates. Daily PWV tendencies are computed as: $\mathrm{dPW}=$ PWV(24 hours $)$ - PWV(0 hours). Most importantly, the consistency between $E$ and $P$ estimates is guaranteed by the use of the $P$ forcing data set used for the LSM simulations.

[8] AMMA Land Surface Model Intercomparison Project (ALMIP) produced a unique regional-scale multimodel ensemble of LSM simulations over West Africa [Boone et al., 2009]. The spatial domain is delimited by $5^{\circ} \mathrm{S}-20^{\circ} \mathrm{N}$ and $20^{\circ} \mathrm{W}-30^{\circ} \mathrm{E}$ and the temporal coverage is $2002-2007$. Nine LSMs have been run offline in the course of the project using the same forcing data set and providing state of the art estimations of various land surface parameters pertinent to water and energy budgets (e.g., $E$, soil moisture and runoff). The 


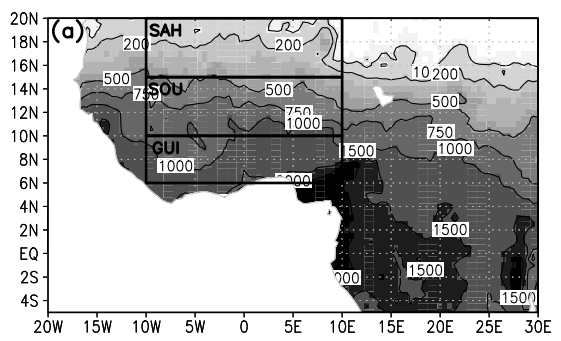

$<_{50} \quad 100 \quad 200 \quad 300 \quad 400 \quad 500 \quad 750 \quad 100015002000$

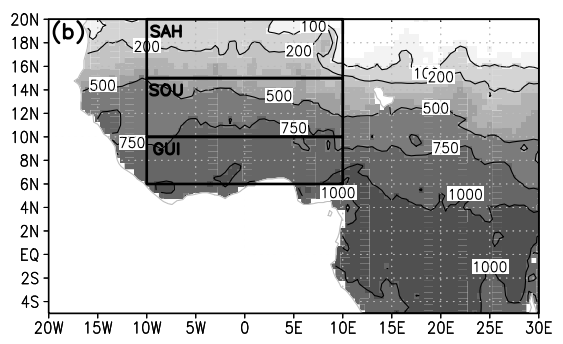

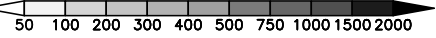
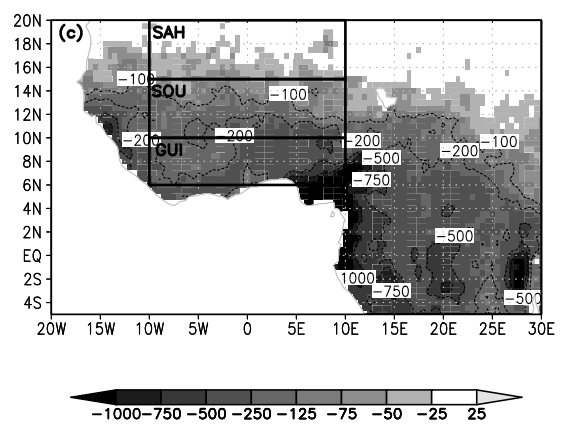

Figure 1. Annual mean over the period 2002-2007 of (a) TRMM precipitation, (b) ALMIP multimodel evapotranspiration, and (c) associated $E-P$ budget. All units are $\mathrm{mm} \mathrm{yr}^{-1}$.

forcing parameters are, in decreasing order of importance: precipitation at the ground, land surface characteristics, downwelling radiative fluxes (shortwave and longwave), and surface meteorological variables $(2 \mathrm{~m}$ temperature and humidity, $10 \mathrm{~m}$ wind, surface pressure).

[9] Three different ALMIP experiments have been produced so far, differing in the precipitation forcing data (the most important). Experiment 1 used only ECMWF forecast precipitation, while experiment 2 used EPSAT-SG [Berges et al., 2010] during the summer period of years 2004-2006 (July-September 2005 and June-September 2004 and 2006) and ECMWF forecast precipitation otherwise. The more recent experiment 3 used in the present study was instead forced all year long and over the whole period (2002-2007) with Tropical Rainfall Measuring Mission 3B42 v6 data [Huffman et al., 2007]. The choice of these products was motivated by the fact that they comply with the high space and time resolutions required for forcing the LSMs ( 3 hourly and at least $0.5^{\circ} \times 0.5^{\circ}$ ), leaving aside other satellite precipitation data sets available at best with coarser temporal sampling. The other forcing data sets are: land surface characteristics (soil type, albedo, vegetation cover fraction, leaf area index, etc.) provided by the ECOCLIMAP database [Masson et al., 2003], downwelling radiative fluxes from ECMWF-Integrated Forecast System (IFS; http://www. ecmwf.int/research/ifsdocs/) in 2002 and 2003, Ocean and Sea Ice-Satellite Applications Facility (OSI-SAF, http:// www.osi-saf.org/) fluxes in summer 2004 and ECMWF-IFS the rest of this year, and fluxes from Land-Satellite Applications Facility (LAND-SAF [Geiger et al., 2008]) in 2005, 2006 and 2007. The surface meteorological variables are from ECMWF-IFS operational forecast.

[10] The quality of ALMIP data set has been assessed in previous studies. Soil moisture estimates were validated at regional scale through indirect comparison with satellite observations (M. Grippa et al., personal communication, 2009). At local scale, sensible heat fluxes were validated from in situ observations from the AMMA field experiment [Boone et al., 2009].

[11] Sensitivity tests (see Appendix A) indicate that at the monthly mean, box average $\left(\sim 10^{6} \mathrm{~km}^{2}\right)$ scales, which is the main focus in this study, the difference in surface schemes between the different LSMs is not a major source of uncertainty as long as they use similar forcing data. Furthermore, in this study, $E_{\mathrm{LSM}}$ is computed from the multimodel average. Such an approach likely reduces the small-scale temporal and spatial variability from each individual LSM simulation but has the advantage of being less model dependent [Koster et al., 2004; Dirmeyer et al., 2006]. The uncertainty in dPW estimates from NWP reanalyses is not a major issue at these scales either. On the other hand, the quality of the precipitation data is of prime importance. The intercomparison of a few satellite products shows a scatter of $\pm 1-2 \mathrm{~mm} \mathrm{~d}^{-1}$ at the scales of interest. But, so far it is difficult to assess which of the precipitation product is the more accurate.

[12] A few recent studies addressed this issue, which is crucial for water cycle studies over West Africa. Nicholson et al. [2003] performed an evaluation of the TRMM 3B43 (merged, monthly) product over West Africa at spatial resolutions of $2.5^{\circ} \times 2.5^{\circ}$ and $1^{\circ} \times 1^{\circ}$, in comparison to gauge data. They report a root mean square (RMS) error in the range 1-2 $\mathrm{mm} \mathrm{d}^{-1}$ for the higher spatial resolution, for the months of July-August. They also found an excess of rainfall in this product around $12^{\circ} \mathrm{N}$ and $15-16^{\circ} \mathrm{N}$ over West Africa (up to $\sim 100 \mathrm{~mm}$ over the season or $50 \mathrm{~mm}$ in August, i.e., $\sim 30 \%$ ). It is possible that the TRMM 3B42 product used in the present study has a similar bias. Berges et al. [2010] used rain gauges observations over the Sahel and evaluated several regional offline products (EPSAT-SG and CPC/RFE2.0), global offline (TRMM 3B42 and GPCP-1dd) and real-time versions of those as well as other products. They found that overall, offline products, and especially EPSAT-SG, performed better than real-time products, consistently with the findings of Nicholson et al. [2003]. The main reason is that these offline products incorporate rain gauge data (so-called blended or merged products) whereas the real-time products, in contrast, are purely satellite-based rainfall estimates. Huffman et al. [2007] find similar results for the real-time and offline versions of the TRMM 3B42 (3 hourly) products. Furthermore, Roca et al. [2010] show that the performance of the products is highly dependent on the time scale considered. Hence, at subdiurnal time scale, TRMM 3B42, appears as the most realistic. These results give thus good confidence into the choice made in ALMIP experiment 3.

\section{Annual Mean and Seasonal Cycle of Water Budget Terms}

[13] The water vapor budget terms are analyzed below for three boxes representative of the West African climate (Figure 1): the Guinean box (GUI) delimited by $6^{\circ} \mathrm{N}, 10^{\circ} \mathrm{N}$, $10^{\circ} \mathrm{W}$, and $10^{\circ} \mathrm{E}$, the Sudanian box (SOU) delimited by $10^{\circ} \mathrm{N}$, $15^{\circ} \mathrm{N}, 10^{\circ} \mathrm{W}$, and $10^{\circ} \mathrm{E}$, and the Sahelian box (SAH), delimited by $15^{\circ} \mathrm{N}, 20^{\circ} \mathrm{N}, 10^{\circ} \mathrm{W}$, and $10^{\circ} \mathrm{E}$. Note that the 
Table 1. Annual Mean (2002-2007) Water Budget Terms $\left(P, E, E-P\right.$, and MFD) in the Three Domains Indicated in Figure $1^{\mathrm{a}}$

\begin{tabular}{lccccccccc}
\hline & $P$ & $E$ & $E-P$ & MFD & $\sigma^{\mathrm{S}}(P)$ & $\sigma^{\mathrm{S}}(E)$ & $r^{S}(E, P)$ & $r^{S}(\Delta P, \Delta E)$ & $r^{S}(\Delta P, \Delta \mathrm{MFD})$ \\
\hline SAH & 239 & 211 & -28 & -29 & 114 & 97 & 0.995 & 0.94 & 0.81 \\
SOU & 726 & 587 & -139 & -137 & 220 & 149 & 0.98 & 0.78 & 0.90 \\
GUI & 1209 & 858 & -351 & -356 & 345 & 83 & 0.62 & 0.69 & 0.95 \\
\hline
\end{tabular}

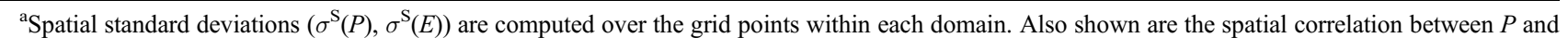
$E\left(r^{\mathrm{S}}(E, P)\right)$ and the spatial correlation between annual anomalies $\Delta P$ and $\Delta E$ and $\Delta P$ and $\Delta \operatorname{MFD}\left(r^{\mathrm{S}}(\Delta P, \Delta E), r^{\mathrm{S}}(\Delta P, \Delta \mathrm{MFD})\right)$. The correlation coefficients are significant at $99 \%$ (student's $t$ test). MFD, moisture flux divergence.

climate of the northern half of the SOU box could alternatively be referred to as Southern Sahelian.

\subsection{Annual Mean Water Budget}

[14] Figure 1 shows the annual mean values of $P, E$, and $E-P$ averaged over period 2002-2007, and Table 1 reports average statistics over the three boxes defined above. Both $P$ and $E$ show a strong zonal symmetry with a large meridional gradient over West Africa. Precipitation ranges from $1209 \mathrm{~mm} \mathrm{yr}^{-1}$ in the GUI box to $239 \mathrm{~mm} \mathrm{yr}^{-1}$ in the SAH box, and $E$ from $858 \mathrm{~mm} \mathrm{yr}^{-1}$ in the GUI box to $211 \mathrm{~mm} \mathrm{yr}^{-1}$ in the SAH box. The SOU box is intermediate. A strong meridional gradient can be seen also in $E-P$, with significant negative values reached in the GUI and SOU boxes, while $E-P \sim 0$ in the SAH box. This can be interpreted as a signature of distinct hydrological regimes. The Sudanian and Guinean regions are characterized by significant runoff $\left(P-E=139 \mathrm{~mm} \mathrm{yr}^{-1}\right.$ in the SOU box and $351 \mathrm{~mm} \mathrm{yr}^{-1}$ in the GUI box). The Sahel is in contrast a more endoreic area where almost all the cumulated rainfall is reevaporated into the atmosphere, on annual mean. The spatial variability in $E$ and $P$ displays distinct meridional properties. Whereas the variability in $P$ shows a marked negative gradient from south to north, $E$ shows a larger variability in the north, with a maximum in the SOU box $\left(149 \mathrm{~mm} \mathrm{yr}^{-1}\right)$. In the SAH and SOU boxes, the spatial correlation between $E$ and $P$ is very high (Table 1). In the GUI box, the spatial correlation is much smaller. This is consistent with the fact that a significant fraction of rainfall escapes in runoff in the GUI box.

[15] Figure 2 investigates further the spatial relationship between $E, P$, and runoff. In the SAH box (Figure 2c), a quasilinear relationship is obtained between $E$ and $P$ (consistently with the high spatial correlation reported in Table 1). The small departure from the $x=y$ axis is explained by runoff (Figure 2f) which is small there: about $60 \mathrm{~mm}$ for a mean rainfall of $500 \mathrm{~mm}$. The relationship between runoff and $P$ is also linear. This is in contrast with the two other boxes and indicates that, in the Sahel, the amount of rainfall is the main limiting factor to $E$. Another contributing factor to decrease in $E$ with increasing latitude is that soils are not as deep (and this is considered in ECOCLIMAP). In the SOU box, where the spatial correlation is close to 1 too (Table 1), the relationship between $P$ and $E$ suggests a saturation for $P$ values above $800 \mathrm{~mm} \mathrm{yr}^{-1}$ (Figure 2b). For the larger rainfall amounts, runoff becomes significant (Figure 2e). In the GUI box, the $E$ versus $P$ diagram shows a superposition of two quasilinear regimes: the first one (for $P<1200 \mathrm{~mm} \mathrm{yr}^{-1}$ ) is relatively close to the regime observed in the SOU box but the second one (for $P>1200 \mathrm{~mm} \mathrm{yr}^{-1}$ ) corresponds to predominant runoff. In contrast with the SOU box though, there is no indication of a saturation in this first regime, and $E$ reaches values up to $\sim 1100 \mathrm{~mm} \mathrm{yr}^{-1}$. The runoff regime concerns mainly the high topographic areas such as Fouta Djalon mountains and Cameroun highlands, which are partly enclosed in the GUI box, but more specifically the southwestern Nigeria plateaus (see $P-E$ maxima in Figure 1). The presence of this double regime in the GUI box explains the rather small spatial correlation reported in Table 1.

[16] Another limiting factor in the amount of $E$ is the net surface radiation $\left(R_{\text {net }}\right)$. However, within the more equatorial GUI box, the spatial distribution of $R_{\text {net }}$ is remarkably homogeneous $\left(\sim 110 \mathrm{~W} \mathrm{~m}^{-2}\right)$ and hence $E$ fluctuates independently of $R_{\text {net }}$. This means that net radiation is not the main controlling factor of the annual mean $E$ there. In the SOU and SAH boxes, a positive correlation between $E$ and $R_{\text {net }}$ emerge, but the relationship between $E$ and $\mathrm{R}_{\text {net }}$ is far from being linear. In the SOU box, there is saturation for values of $E>500 \mathrm{~mm}$, corresponding to the largest values of $R_{\text {net }}$ (similar to GUI box). In the SAH box, such large values are not reached.

[17] The analysis of annual mean quantities revealed close relationships between the spatial distributions of water budget components $(E, P$, and runoff) and net radiation at the surface. However, an important factor in the functioning of the hydrological cycle is masked here. It is the time distribution of rainfall and net radiation. In the Sudanian and Sahelian regions, the seasonal cycle plays a crucial role in the water budget as it is shown below.

\subsection{Mean Seasonal Cycle}

[18] Figure 3 displays the seasonal cycle of the monthly mean water and radiation budget components. The upper row of Figure 3 highlights the atmospheric water budget. In agreement with previous studies, there is evidence of two distinct rainfall regimes over the relatively moist Guinean area and over the more arid regions to the north. In the GUI box, rainfall is characterized by two maxima occurring in June and September. In the SOU and SAH boxes, there is a single rainfall maximum in August. This phasing is explained by the seasonal excursion of the rainbelt which reaches its northernmost position in August over the Sahel [Sultan and Janicot, 2000]. The magnitudes of the rainfall maxima are nearly identical in the GUI and SOU boxes $\left(\sim 6 \mathrm{~mm} \mathrm{~d}^{-1}\right)$, but the duration of the rainy season is much longer in the GUI box. This accounts for the large differences in the annual means (Table 1). In the SAH box, both the maximum and the duration of the season are significantly smaller.

[19] A high degree of correlation is observed between $E$ and $P$. In the GUI box, the seasonal cycle of $E$ is thus nearly bimodal, while it is monomodal in the SOU and SAH boxes. In terms of magnitude, in the GUI box, $E>1.5 \mathrm{~mm} \mathrm{~d}^{-1}$ all year long, with an average of $2.2 \mathrm{~mm} \mathrm{~d}^{-1}$ and maxima of 

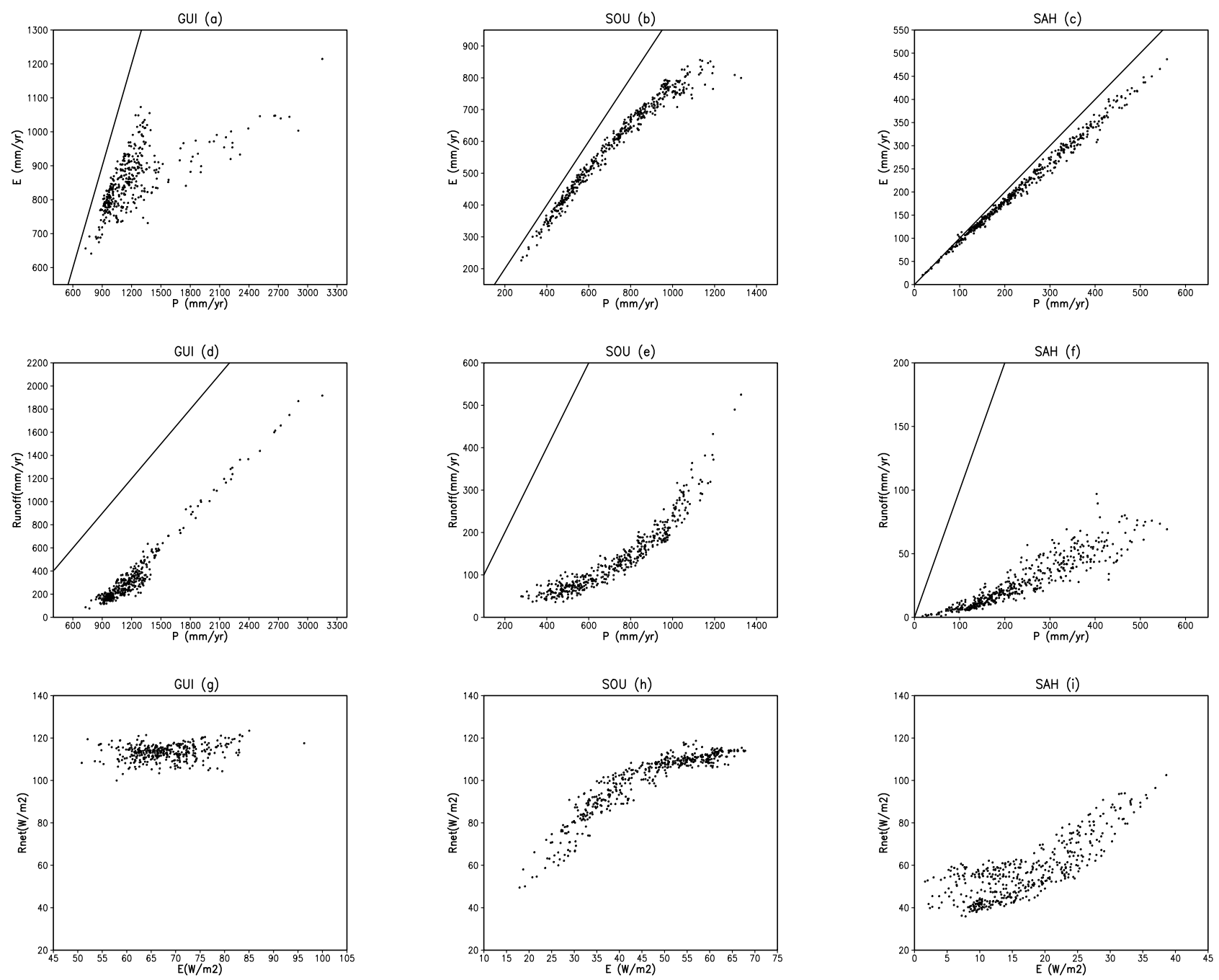

Figure 2. Scatterplots of annual mean quantities (2002-2007): (a-c) evaporation versus precipitation (in $\left.\mathrm{mm} \mathrm{yr}^{-1}\right),(\mathrm{d}-\mathrm{e})$ runoff versus precipitation (in $\left.\mathrm{mm} \mathrm{yr}^{-1}\right)$, and $(\mathrm{g}-\mathrm{i})$ net radiation at surface $\left(\mathrm{W} / \mathrm{m}^{2}\right)$ versus evaporation $\left(\mathrm{mm} \mathrm{yr}^{-1}\right)$ for grid points located in the three domains indicated in Figure 1.

3-3.5 $\mathrm{mm} \mathrm{d}^{-1}$ in June and October. Larger rainfall amounts coupled to a weaker seasonal cycle of vegetation in the Guinean area is the main cause for the nearly constant $E$. In the SOU box, $E$ reaches $3.5 \mathrm{~mm} \mathrm{~d}^{-1}$ in September, while in the SAH box, $E$ peaks in August and hardly reaches $2 \mathrm{~mm} \mathrm{~d}^{-1}$. In the SOU and SAH areas, $E$ drops to $\sim 0$ during the dry season. These $E$ limits agree well with observations by Timouk et al. [2009] and with independent LSM estimations by Saux-Picart et al. [2009].

[20] The contribution of atmospheric processes to the seasonal evolution of the precipitation is quantified on average through dPW and MFD. Though it is small in amplitude, dPW shows a distinct seasonal cycle with positives values during the monsoon preonset period (February-March in GUI box, April-May in SOU box, and May-June in SAH box) and negative values during the monsoon retreat. This tendency results from the seasonal excursion of the moist monsoonal air mass. The northernmost limit is associated with the intertropical discontinuity (ITD). The evolution of MFD is highly anticorrelated with that of $\mathrm{P}$, indicating that, on the monthly mean time scale, precipitation is significantly controlled by atmospheric moisture convergence $(\mathrm{MFD}<0)$ during the rainy season. During the dry season, moisture divergence is observed (MFD $>0$ ), revealing that the surface is a net source of moisture for the atmosphere, then. This result is consistent with the balance between $E$ and $P$ (by construction). In terms of magnitude, MFD reaches $-4 \mathrm{~mm}$ $\mathrm{d}^{-1}\left(+2 \mathrm{~mm} \mathrm{~d}^{-1}\right)$ in the SOU and GUI boxes and $-1 \mathrm{~mm} \mathrm{~d}^{-1}$ $\left(+0.5 \mathrm{~mm} \mathrm{~d}^{-1}\right)$ in the SAH box during the wet (dry) season.

[21] In terms of balance between the four water budget terms, significant differences are found between the three boxes. In the GUI and SOU boxes, -MFD is larger than E, while in the SAH box, $E$ is larger than -MFD. This difference reveals different surface-atmosphere interactions in addition to the fact that different atmospheric dynamical factors are controlling the rainfall in the Sahel [Fontaine et al., 1995; Grist and Nicholson, 2001; Zhang et al., 2006; Ruane and Roads, 2008]. The temporal evolution of $E$ is not only dependent on precipitation input but it also depends on the surfacevegetation response [Lotsch et al., 2003]. This explains the time lag observed in $E$ with respect to $P$ (Figure 3). The lag was quantified from mean cross-correlation functions (on 

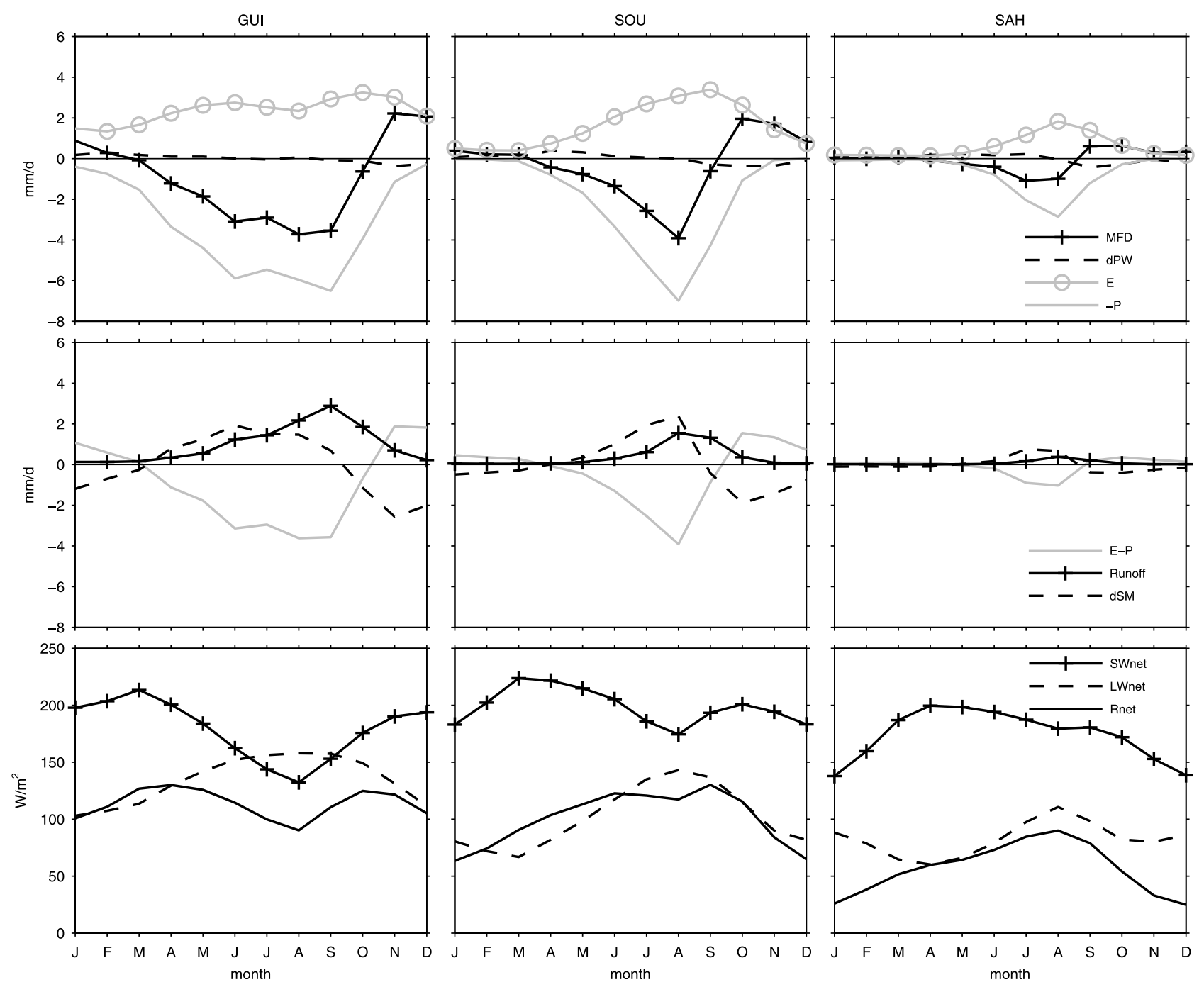

Figure 3. Monthly mean water and energy budget terms (2002-2007): (top) atmospheric water budget terms (in $\mathrm{mm} \mathrm{d}^{-1}$ ), (middle) surface water budget terms (in $\mathrm{mm} \mathrm{d}^{-1}$ ), and (bottom) net radiation and $\mathrm{LW}$ $\left(+200 \mathrm{~W} / \mathrm{m}^{2}\right)$ and SW components at the surface $\left(\right.$ in $\left.\mathrm{W} / \mathrm{m}^{2}\right)$. All quantities are spatial averages in the three domains indicated in Figure 1.

average over the six years). The correlations peaked at +1.5 month in the GUI box, +1 month in the SOU box and $\sim 0$ month in the SAH box. These lags indicate that the response of the surface-vegetation system to the monsoonal rainfall is faster in the Sahel than more to the south. This is confirmed by inspection of vegetation index and soil moisture [Janicot et al., 2008, Figure 24]. Moreover, deeper soils in the GUI box will cause $E$ and $P$ to be more decorrelated (or at least have a larger lag) because $E$ can continue for extended periods after the rains have stopped. Indeed, $E$ integrates several distinct processes in the soilsurface-vegetation system such as rapid evaporation from rain intercepted by the canopy, but also slower and delayed evaporation from the soil and especially transpiration from vegetation (deeper soil storage reservoirs). The latter is more delayed in the SOU and SAH regions than in the GUI region because it requires soil moisture recharge and vegetation growth [Shinoda, 1995; Nicholson et al., 1990]. Both processes are strongly controlled by the temporal distribution of rainfall within the season and hence may play a role in the interannual variability of $E$ (see section 4).

[22] Inspection of the monthly mean surface water balance (Figure 3, middle) shows a clear contrast with the annual mean balance (Figure 1). Indeed, it is seen here that $E-P$ is only negative during the wet season while it is positive during the dry season. This is observed for all three boxes, highlighting again strong large-scale surface-atmosphere couplings. The seasonal evolution of runoff and soil moisture storage (dSM $=P-E$ - runoff), is significant as well (the latter was found to be in good agreement with GRACE data (M. Grippa et al., personal communication, 2009)). These terms show a monthly mean seasonal cycle which closely follows that of $P$. The soil moisture dynamics is strong, with a magnitude of dSM which can be as large as the other budget terms, in contrast to a negligible atmospheric water vapor storage. Runoff is nearly monomodal and maximum at the end of the rainy season in the GUI and SOU regions.

[23] The link between net surface radiation and $E$ is investigated from the lower part of Figure 3 which displays 

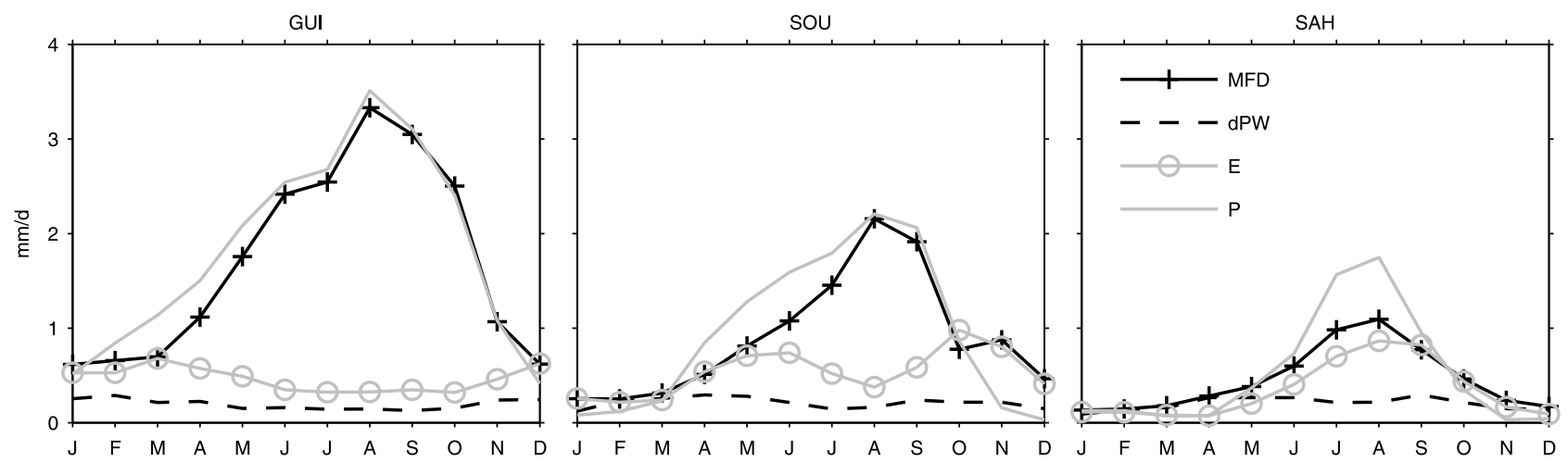

Figure 4. Standard deviation of spatial distribution of monthly mean atmospheric water budget terms for grid points located in the three domains indicated in Figure 1. The standard deviation is computed for each year and then averaged over 2002-2007.

the net shortwave (SW) and longwave (LW) components, and net radiation $\left(R_{\text {net }}=\mathrm{SW}+\mathrm{LW}\right)$. The seasonal evolution of $R_{\text {net }}$ partly explains the fluctuations of $E$ in all three regions. However, the relationship is not simple because many factors operate in the surface energy budget [Roads and Betts, 2000]. The seasonal evolutions of SW and LW components are broadly in phase opposition. The SW component is modulated by the seasonal cycle of the solar incoming radiation, the atmospheric transmittance (i.e., aerosol content and cloud fraction), and surface albedo. The LW component is modulated by surface temperature and emissivity, atmospheric water content (vapor and clouds) and aerosols. All these parameters exhibit a marked seasonal cycle and strong couplings [e.g., Guichard et al., 2009; Slingo et al., 2009]. Our results are consistent with the parts of these studies which were focused on areas located within the SAH and SOU boxes. They further suggest a distinct functioning in the GUI region, where the most striking difference is the large drop in net SW radiation, and $R_{\text {net }}$, between May and September. This is most likely due to increased cloudiness as the rainbelt is located around $10^{\circ} \mathrm{N}$ then [Sultan and Janicot, 2000]. It is also noticeable that SW does not increase much northward though, despite smaller cloud covers there; this feature likely involves the meridional gradient of albedo [Samain et al., 2008]. Thus, LW plays a significant role with respect to the overall decrease of $R_{\text {net }}$ with latitude. This is coherent with the findings of Fontaine et al. [2002], who stated that the LW flux decreases during the season due to the moistening of the soil.

[24] The spatial variability of the budget terms (Figure 4) reveals different seasonal cycles in all three boxes. Rainfall variability is larger than that of $E$ and PWV tendency terms, but comparable to MFD. In the SOU and GUI boxes, MFD explains most of the variability in $P$. In both areas, $E$ is slightly bimodal. This is especially the case in the SOU box, with maxima in May and October. These maxima can be explained by the changes in the surface-vegetation properties associated with the monsoon onset (fast response of the vegetation to the preliminary rain events) and retreat (fast decay of the vegetation after the end of the season, especially in the SOU box). The large variability in $E$ is explained by similar considerations for the SAH and SOU boxes. A major difference however (monomodal versus bimodal structure) is due to the shortness of the rainy season in the SAH area. In the core of the monsoon season, the spatial variability of $E$ is very low in the SOU box, which is illustrated for August in Figure 5. In contrast, $P$ shows a rather narrow band of stronger values between $10^{\circ} \mathrm{N}$ and $12^{\circ} \mathrm{N}$, corresponding to the location of the rainbelt and closely linked to zone of maximum MFC. The displacement between the zones of maximum $E$ and $P$ is actually linked to the spatial distribution of $R_{\text {net. }}$ Figure 5 shows that the net radiative flux maximum is observed slightly to the north of the rainbelt, i.e., where cloud cover and rainfall are smaller. Rainfall is also reduced in the southern part of the GUI box, corresponding to the short dry season in August there [Sultan and Janicot, 2000]. In contrast with the GUI and SOU boxes, the SAH box shows similar variability in MFD and $E$.

\subsection{Submonthly Variability}

[25] The monthly mean water budget terms analyzed above reveal a significant seasonal modulation in MFD which is correlated with the cumulated rainfall. However, the magnitude of MFD is smaller in the SAH region, especially compared to the monthly $E$ values. More insight into the underlying atmospheric processes is given here.

[26] Figure 6 shows the day-to-day variability of the different water budget terms which gives some insight into the strength of these processes. It is seen that MFD is the term that exhibits the strongest temporal variability in all three boxes with a peak during the rainy season $\left(3-5 \mathrm{~mm} \mathrm{~d}^{-1}\right)$. The coupling between MFD and the other variables is here interpreted from physical point of view, though the apparent coupling may be partly influenced by the fact that MFD is derived as residual of the budget equation. It is seen that the GUI and SOU boxes, the variability of $P$ and MFD are coupled and dominate during the wet season, while during the dry season, the variability of $\mathrm{dPW}$ is mostly explained by MFD. In the SAH box, the variability of MFD is the major contributor to the variance of $\mathrm{dPW}$, all year long. Compared to the variances of these three terms, the variance of $E$ is weak (also seen at a more local scale in Figure 5). This is explained by several limiting factors in $E$ (atmospheric demand, marked diurnal cycle and spatial variability smoothed out when passing to daily means and box averages). It is thus suggested that the short-term variability of the regional-scale water cycle is strongly controlled by the underlying atmospheric processes. This does not preclude, however, that at seasonal time scale $E$ has a strong weight in the water budget (see 

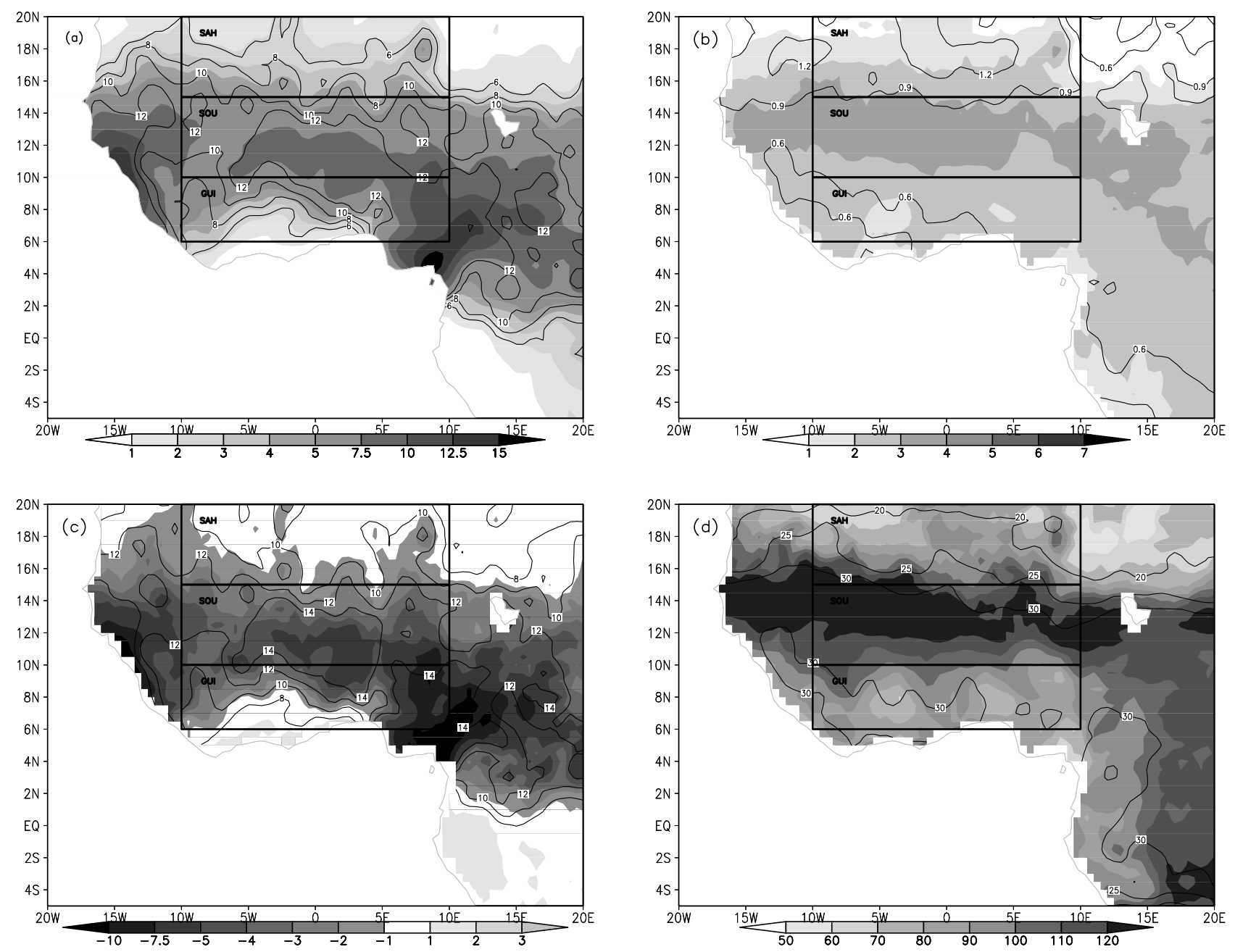

Figure 5. Mean month of August (2002-2007) of (a) precipitation (in $\mathrm{mm} \mathrm{d}^{-1}$ ), (b) evapotranspiration (in $\mathrm{mm} \mathrm{d}^{-1}$ ), (c) moisture flux divergence (in $\mathrm{mm} \mathrm{d}^{-1}$ ), and (d) net radiation at the surface (in $\mathrm{W} / \mathrm{m}^{2}$ ). Contours indicate the day-to-day variability (standard deviation of daily mean computed for each year and then averaged over 2002-2007).
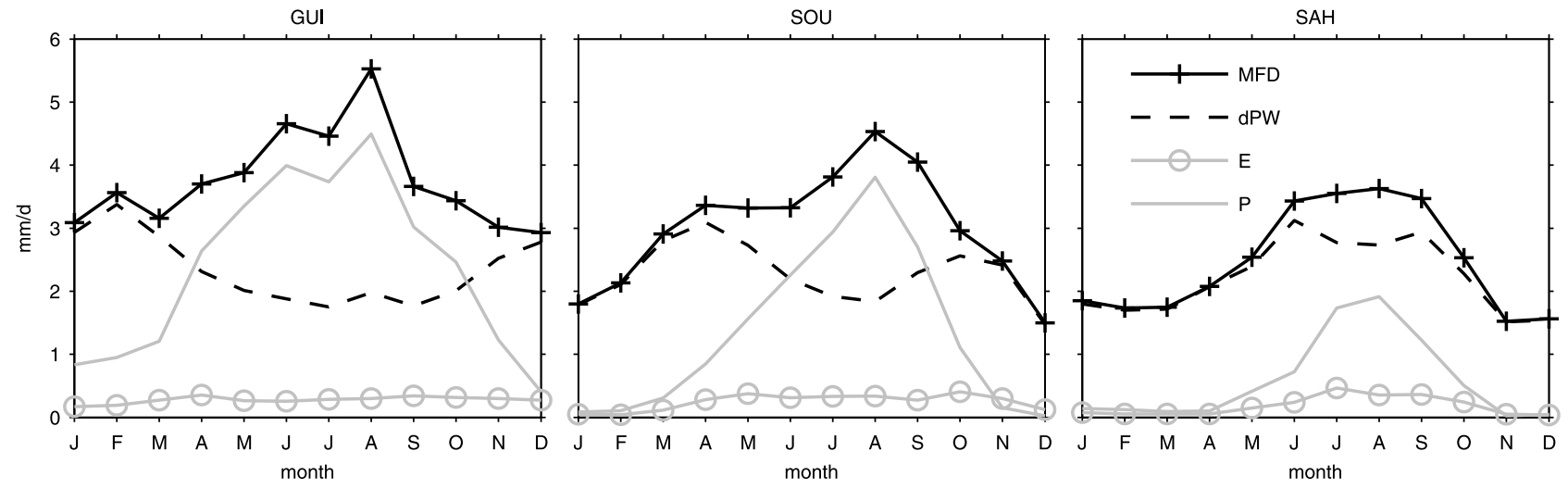

Figure 6. Standard deviation of temporal variability (daily mean) atmospheric water budget terms averaged over the three domains indicated in Figure 1. The standard deviation is computed for each year and then averaged over 2002-2007. All units are $\mathrm{mm} \mathrm{d}^{-1}$. 

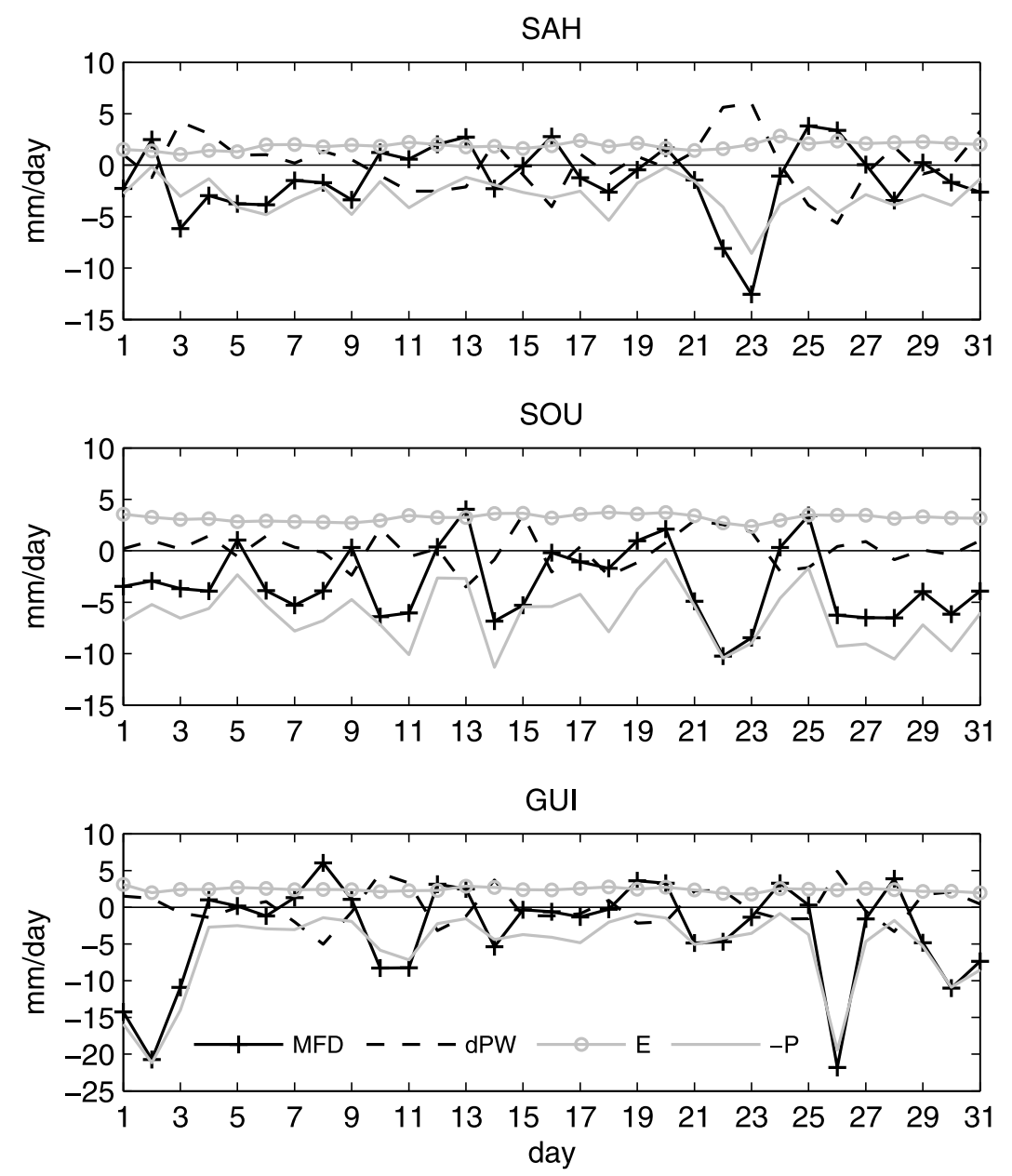

Figure 7. Daily mean atmospheric water budget components (in $\mathrm{mm} \mathrm{d}^{-1}$ ) for August 2006.

Figure 3) and that at small spatial scales the surfaceatmosphere feedbacks are significant as well [Polcher, 1995; Taylor and Lebel, 1998].

[27] In all three boxes, dPW variability decreases during the core of the rainy season. This can be explained by the large PWV values which leads to relative humidity values close to saturation. In contrast, during the dry season, strong $\mathrm{dPW}$ variability is observed in the GUI and SOU boxes due to the advection of large amounts of moisture from the Atlantic Ocean imbedded in large-scale atmospheric circulation patterns [Bock et al., 2008]. The typical time scales of PWV variations during the rainy season and dry season are notably different. Note that Figure 6 reproduces fairly well the variability observed at the local scale with GPS data in the Sahelian and Guinean regions (Figures A3 and A4).

[28] In order to better understand the nature of the day-today variability of the different water budget terms, we show in Figure 7 an example time series for August 2006. In the Sahel, it is seen that MFD can experience positives and negative values anticorrelated with the PWV tendency variations most of the time, revealing the alternation of dry and moist advections. Moisture flux divergence (MFD $>0$ ) often suppresses convective development while moisture flux convergence $(\mathrm{MFD}<0)$ is more favorable to the development of convection. In the GUI and SOU boxes, positives values of
MFD (i.e., moisture divergence) are weaker than negative values (convergence) which are most of the time associated with significant rainfall, in general agreement with Bielli and Roca [2009]. The largest values of moisture divergence are 5-6 $\mathrm{mm} \mathrm{d}^{-1}$, in August, whereas moisture convergence can reach values up to $10-20 \mathrm{~mm} \mathrm{~d}^{-1}$. As a consequence, monthly averages of MFD will have larger values in the SOU and GUI than in the SAH box. Spatial averaging also results in smoothing the MFD signal as revealed in the two-dimensional plots of MFD and $P$ at a daily resolution (not shown).

[29] Finally, vertical integration even further smooths the signature of moisture convergence-divergence associated with MCSs. Mesoscale convective systems have a typical life time on the order of 12 hours [Mathon et al., 2002]. Their instantaneous vertically resolved water budget terms show strong stratification with drying and moistening layers associated with condensation of water vapor and evaporation of precipitation as well as vertical moisture advection [Caniaux et al., 1994; Guichard et al., 1997]. Moreover, the convective and stratiform parts of a MCS show a distinctly different balance between these terms. The alternation between positive and negative values of vertically integrated MFD shown in Figure 7 therefore reveals only the dominant feature of these processes, but it is worth noting that the resulting signal 

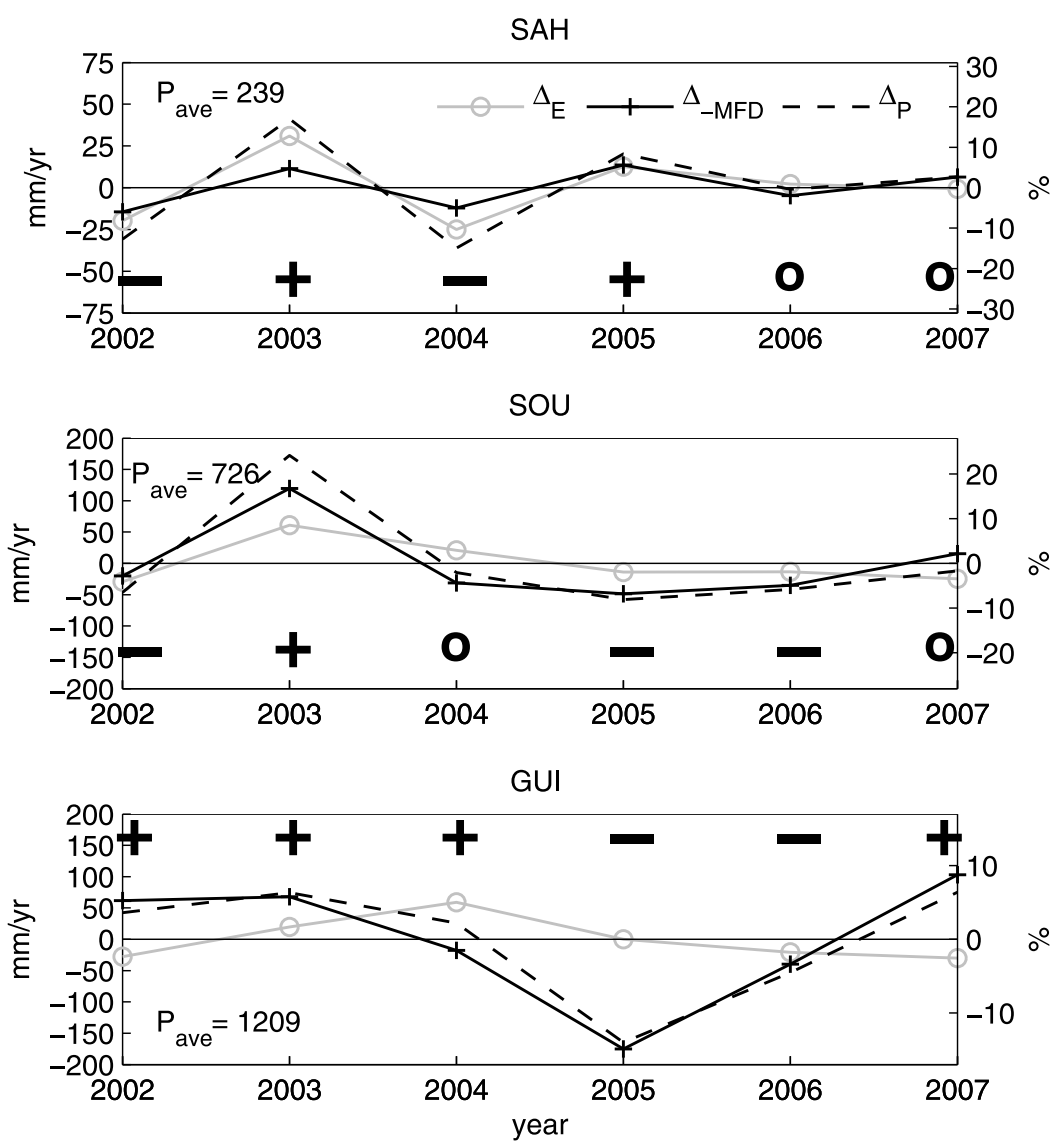

Figure 8. Annual mean anomalies in precipitation $(\Delta P)$, evapotranspiration $(\Delta E)$, and moisture flux convergence $(-\triangle M F D)$ over the three domains indicated in Figure 1. Positive (negative) signs indicate the type of precipitation anomaly related to the mean annual precipitation (left corner) over the period 2002-2007.

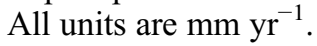

is nevertheless significantly strong. A similar conclusion holds for monthly mean MFD values observed in Figure 3.

\section{Interannual Variability of the Water Budget}

\subsection{Annual Mean Quantities and Anomalies}

[30] Figure 8 displays the variation of the annual mean water budget term anomalies in each box. The anomalies are computed with respect to the 6 year period (2002-2007), but they are fairly consistent with those computed by Ali and Lebel [2009] over a longer time period. Here the anomalies are computed for annual means instead of just from the rainy season means. This is more consistent for lagged terms such as $E$ (i.e., the results are not sensitive to a truncation within the seasonal cycle of $E$ ). Inspection of $P$ anomalies shows that the SAH box records 2 wet years, the SOU box only 1 wet year and the GUI box records 4 wet years and 2 dry years. Among these, 2003 was a wet year everywhere, while 2006 was dry almost everywhere (except in the SAH where it was neutral). Years 2002 and 2004 were dry dipole years [Janicot, 1992a, 1992b; Nicholson, 2009], with SAH and SOU dry, and GUI wet. 2007 was mostly wet in GUI, and 2005 was a wet dipole year (SAH wet, SOU and GUI dry). Thus, whether a year is dry or wet is highly region dependent. The question here is how are anomalies of the different water budget term correlated?
[31] Overall, $\Delta P$ and $-\Delta$ MFD are positively correlated in all three boxes, e.g., increased precipitation coincides with increased moisture flux convergence. This is in agreement with Fontaine et al. [2003] and highlights the importance of the impact of the atmospheric dynamics on the interannual variability of precipitation over West Africa. Both the temporal correlations, seen in Figure 8, and the spatial correlation coefficients, reported in Table 1, confirm a strong link between $\Delta P$ and $-\Delta$ MFD in all three boxes, but these correlations have a different latitudinal dependence. In terms of magnitude, the variability of the annual mean $\Delta \mathrm{P}$ is on the order of $10 \%-20 \%$ of the total rainfall. In the GUI and SOU boxes, rainfall anomalies are thus almost entirely balanced by moisture flux convergence anomalies. This is not the case in the SAH box where the annual mean MFD is close to zero (and $E \sim P$ as already seen above). When considering the month of maximum rainfall for each year in the SAH box, it is found that $-\Delta \mathrm{MFD} / \Delta P \approx 0.9-1.0$ from 2002 to 2004 , with magnitudes of $-\triangle \mathrm{MFD}= \pm 10-20 \mathrm{~mm} \mathrm{month}^{-1}$ (not shown). The spatial correlation of MFD and $P$ is further illustrated in Figure 9 from the June-September mean for this 6 year period. In 2003 and 2007, both the rainbelt and the associated band of moisture convergence are broader and extending more to the north. In 2002, 2004, and 2006, they are both weaker and more confined to the south. In 2005, they are both weaker and displaced more to the North. 

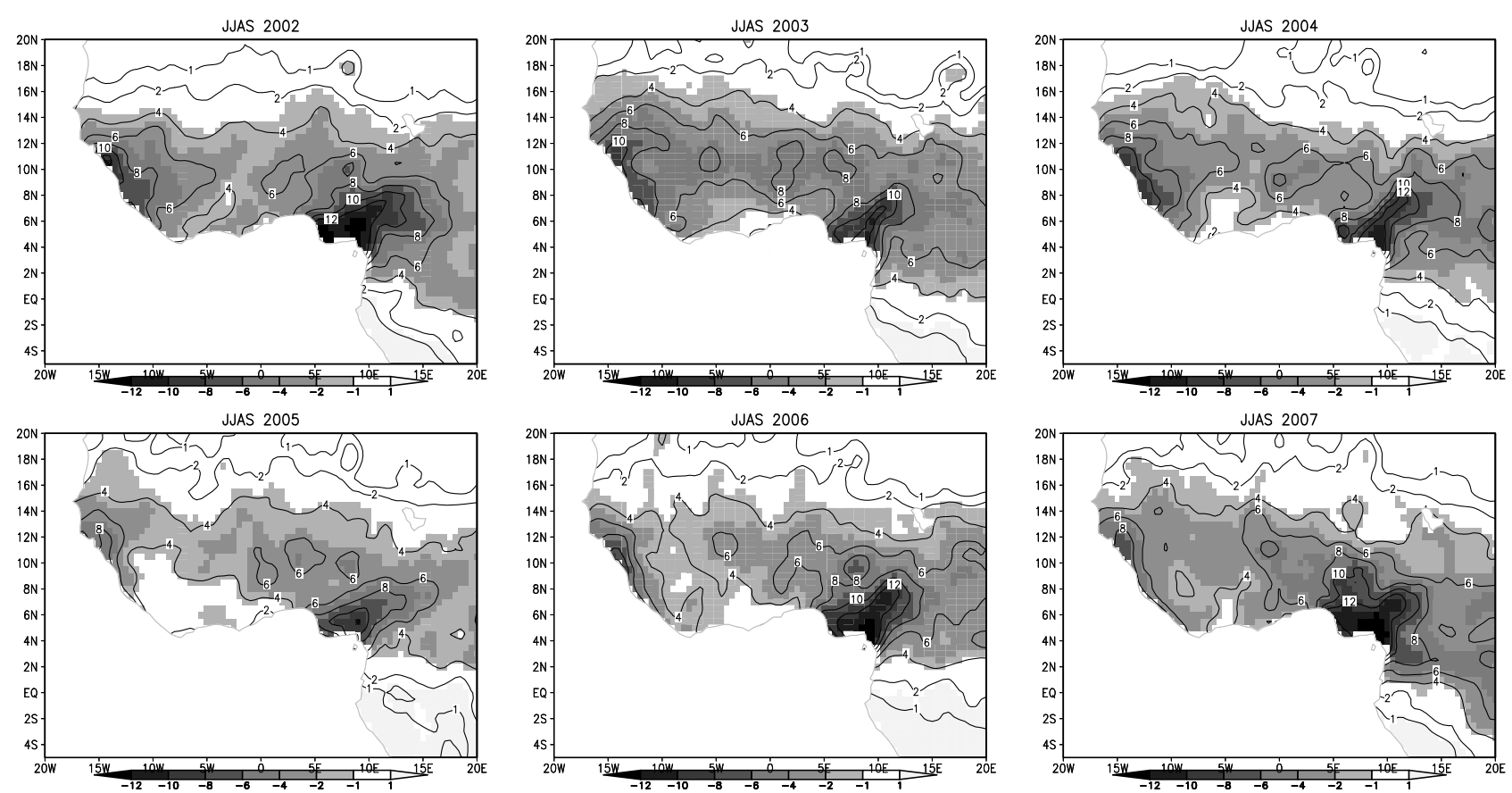

Figure 9. Moisture flux divergence (shaded) and precipitation (contours) averaged over the period from June to September of each year.

[32] Both the spatial and temporal correlations between $\triangle E$ and $\Delta P$ are decreasing from the $\mathrm{SAH}$ box to the GUI box. The temporal covariability, especially, is very low in the GUI region (Figure 8) and is a result of the strong response of runoff to precipitation variations there (section 3 and Figure 2). The moderate spatial correlation between $\Delta \mathrm{E}$ and $\Delta P$ in the GUI box (Table 1) is in contrast with the low temporal correlation. The larger covariability between $\triangle P$ and $\Delta E$ in the SOU and $\mathrm{SAH}$ boxes implies stronger surface-atmosphere interactions and suggests that local water recycling may play a significant role in the interannual variability in rainfall observed in these regions.

\subsection{Interannual Variability of the Seasonal Cycle}

[33] The intermittency of rainfall is an important factor responsible for the interannual variability of cumulated rainfall [Lebel et al., 2003]. This aspect is assessed here from inspection of fluctuations in the seasonal cycle of the water budget terms.

[34] Figure 10 presents time series of monthly mean water budget components for the years 2002 to 2007. Precipitation shows a strong interannual variability in the shape of the seasonal evolution. This is especially true over the GUI region where the two maxima in June and September seen in the mean seasonal cycle (Figure 3 ) disappear in some years. In the SOU and SAH regions the shape of the seasonal cycle of $P$ always peaks in August but both the magnitude of the maximum and the length of the rainy season are strongly varying. In 2003, seen as the wettest year between 2002 and 2007 over West Africa (Figure 8), the rains start early in the GUI region, are exceptionally heavy during the summer in the SOU and SAH areas, and are long lasting everywhere. In 2007 , the maximum of precipitation rate is of the same order as 2003 in the SOU and SAH boxes but the length of the rainy season is shorter, explaining thus why 2007 does not appear anomalous in Figure 8 . The correlation between annual mean $P$ anomalies and anomalies of the maximum $P$ or the length of the rainy season are thus quite poor. This result is consistent with those reported for more extended periods by Lebel et al. [2003].

[35] The seasonal evolution of MFD displays also strong interannual variability with overall close correlation with fluctuations in $P$. For instance, 2003 is marked by a longer moisture flux convergence period and a stronger maximum in August for the SOU and SAH regions, and in June and September in the GUI box. In 2005 (wet dipole year), the period of time when MFD $<0$ in the Sahel lasts longer as well, with also a peak of moisture flux convergence in June, not seen in the other years.

[36] The time series of $E$ is both shaped by variability in $P$ and $R_{\text {net }}$ and shows strong interannual variability. In the $\mathrm{SAH}$ box, the maxima of $E$ well in phase with maxima of $\mathrm{P}$, confiming (see Figure 2) that $E$ is primarily controlled by soil moisture availability and thus precipitation there. In the GUI region, $E$ is always bimodal which suggests a predominant role of $R_{\text {net. }}$ In the SOU region both $P$ and Rnet have strong impact. For example, in 2004, a peak is seen in $E$ in September, while $P$ is anomalously low (it was classified as a dry year in Figure 8). This peak is explained by an anomalously high Rnet (Figure 10d) which is probably a result of reduced cloudiness during this dry year. More generally, the correlation coefficients of the maxima of $E$ and the corresponding values of $R_{\text {net }}$ are as follows: $r=0.9$ in GUI, 0.9 in SOU, and 0.7 in SAH boxes.

[37] The time series of $R_{\text {net }}$ exhibits also marked interannual variability which is partly controlled by could cover and hence correlated with precipitation. As a consequence, inspecting the surface radiative budget is useful for interpreting 

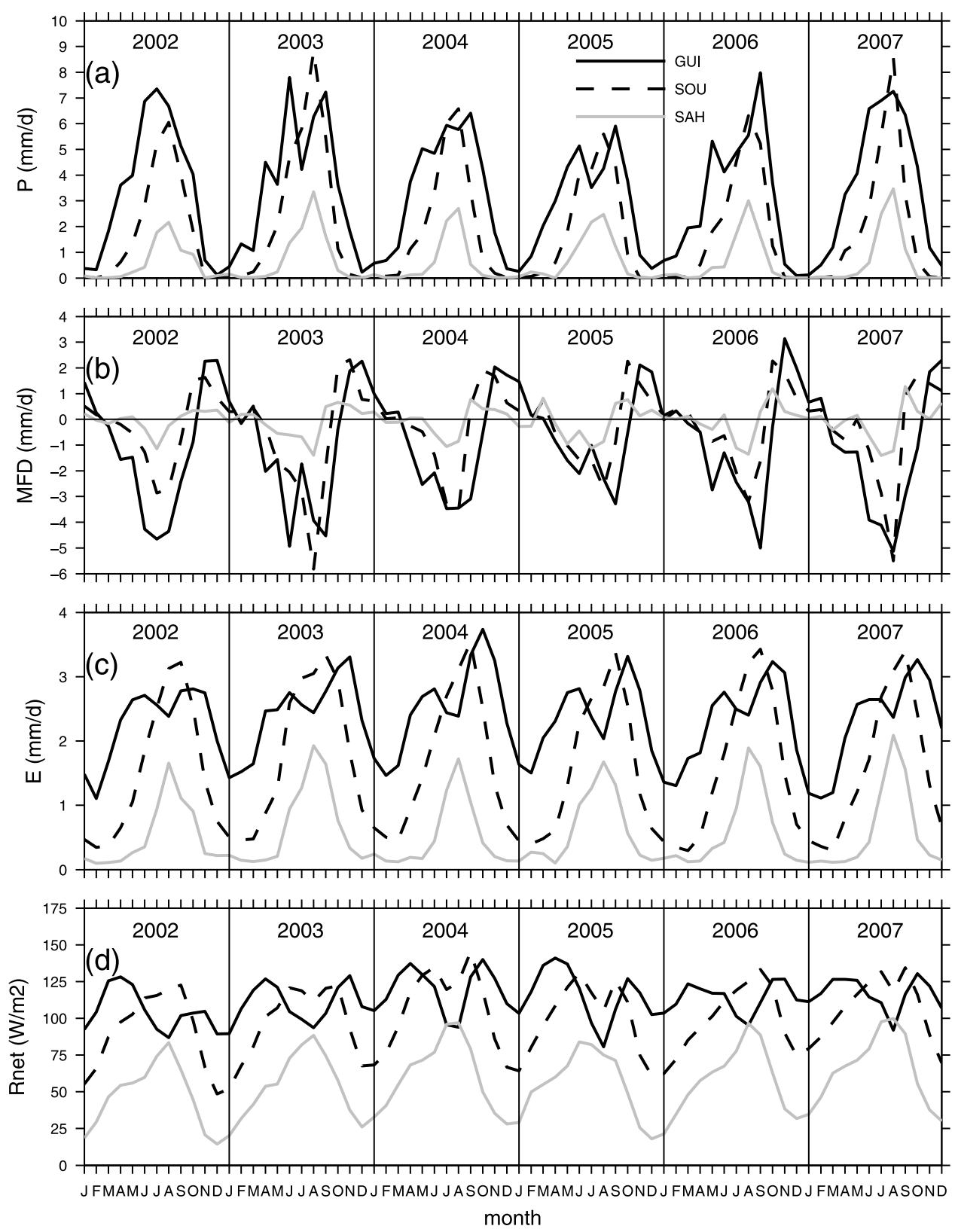

Figure 10. Monthly mean time series of (a) precipitation $\left(\mathrm{mm} \mathrm{d}^{-1}\right)$, (b) moisture flux divergence (in mm $\left.\mathrm{d}^{-1}\right)$, (c) evapotranspiration $\left(\mathrm{mm} \mathrm{d}^{-1}\right)$, and (d) net radiation at the surface $\left(\mathrm{W} / \mathrm{m}^{2}\right)$ for the three domains indicated in Figure 1.

variability in the water budget. However, the relationship between water and energy budget terms is not so simple.

\subsection{Interrelations Between Monthly Anomalies}

[38] The causality between seasonal cycle anomalies in the different budget terms is further investigated with lag correlations of monthly mean anomalies. Figure 11 presents such correlation functions (these correlations have been tested at the two-sided 0.05 and 0.01 levels using a random phase test [Ebisuzaki, 1997]).

[39] In the SAH box, the strongest correlations are observed between $\Delta P$ and $\Delta E$ for lags of -1 and 0 month (negative lag meaning that $\Delta P$ leads $\Delta E$ ) and between $-\triangle \mathrm{MFD}$ and $\triangle \mathrm{dPW}$ with 0 lag. The third most significant correlation is observed between $\Delta P$ and $-\Delta M F D$, it is positive with a lag of +1 month and negative with a lag of -1 month. These results indicate that in the Sahel a rainfall anomaly in a given month is preceded by a moisture convergence anomaly of same sign 1 month ahead and followed by a moisture convergence anomaly of opposite sign 1 month after. Rainfall anomalies are also followed by $E$ anomalies, 1 month later. Moisture convergence anomalies are very strongly correlated with PWV tendency anomalies. The correlation function shows actually oscillations with a pseudoperiod of 3-4 months, corresponding to the duration of the monsoon season. 

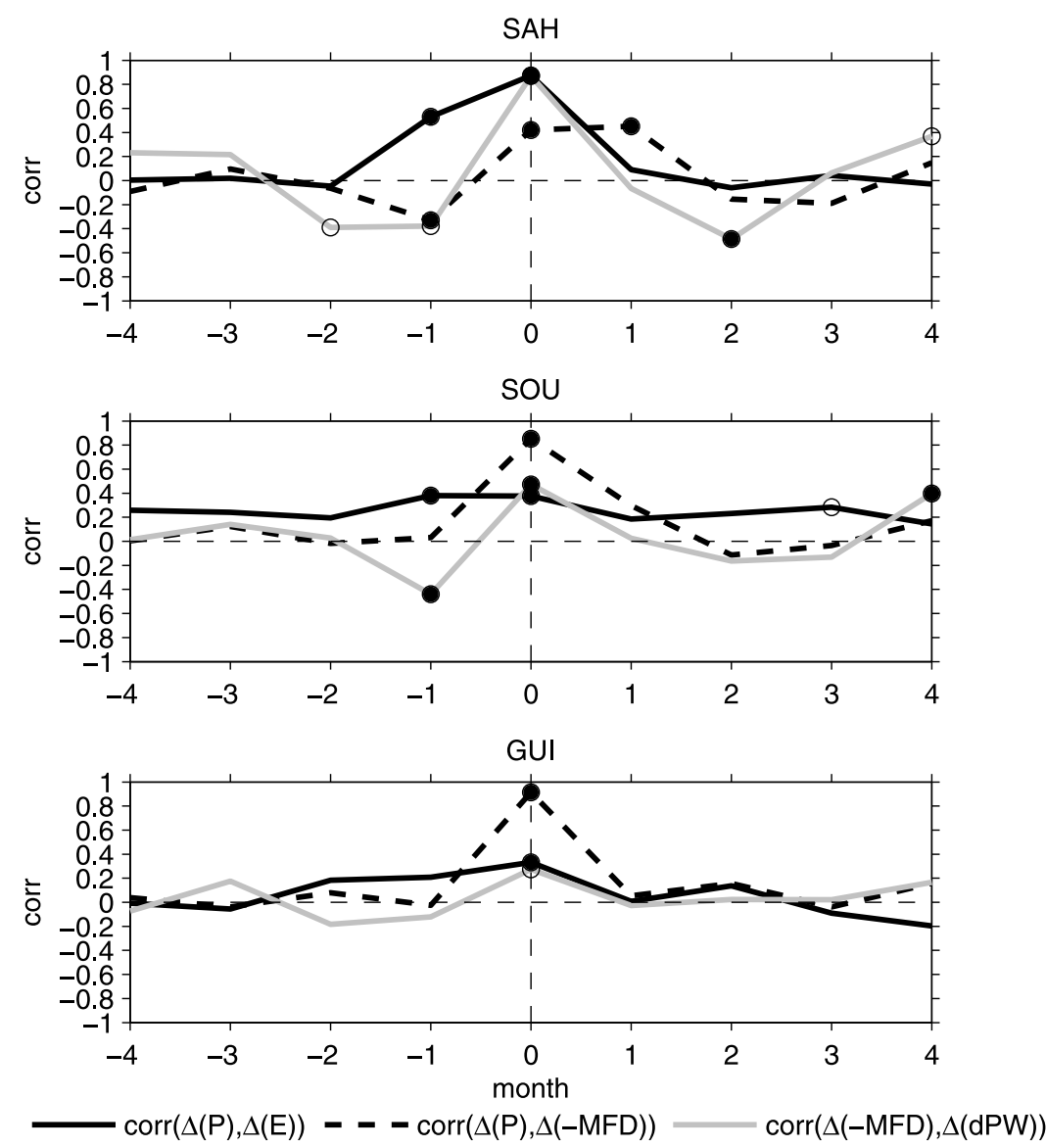

Figure 11. Lagged correlation functions of monthly mean anomalies of water budget terms. A negative lag means that the first variable leads the second one. The filled (open) circles are significant at the two-sided $0.01(0.05)$ level according to a random-phase test [Ebisuzaki, 1997].

[40] In the SOU and GUI boxes, the causality is different. The strongest correlations $(r \geq 0.8)$ are observed between $\Delta P$ and $-\triangle$ MFD with 0 lag, whereas it is lagged in the SAH box. In the SOU box, the second significant correlation $(r \sim 0.4)$ is observed between $-\triangle \mathrm{MFD}$ and $\Delta \mathrm{dPW}$, positive with 0 lag and negative with a lag of -1 month. This is similar to the SAH box, but correlation coefficients are smaller. Similar to the SAH box also, in both the SOU and GUI boxes, $\Delta P$ and $\Delta E$ are positively correlated with a negative lag, but the strength of this correlation is much weaker. The interrelations between monthly budget term anomalies are very similar to those derived from annual mean anomalies, but the lagged correlations clearly evidence some causality between terms. Overall, the interrelations between the terms are stronger and exhibit longer time correlations (up to a few months) in the SAH box, revealing mainly that rainfall strongly controls evapotranspiration at submonthly scale.

\section{Discussion and Comparison With Other Studies}

\subsection{Annual Mean and Seasonal Cycle}

[41] Comparison of our results with past studies reveals that the most striking difference comes from the $E$ estimates. Willmott et al. [1985] and Nicholson et al. [1997] estimate annual $E$ to $\sim 1200 \mathrm{~mm} \mathrm{yr}^{-1}$ between $5^{\circ} \mathrm{N}$ and $10^{\circ} \mathrm{N}$. These are significantly larger than those found in the present study, especially in the Sudano-Guinean zone, whereas the $P$ estimates agree well, except to the very south (but this might be due to the difference of periods considered). Consistent with the present study, these authors found a strong spatial correlation between $P$ and $\mathrm{E}$, and runoff close to zero in the Sahel. However, their meridional runoff gradient is smoother and their runoff estimate is $\sim 100 \mathrm{~mm}$ smaller in the SudanoGuinean zone. In terms of seasonal cycle, Nicholson et al. [1997] present estimates at three stations representative of our three boxes. Their monthly mean $E$ estimates are superior by a factor 1.4 to 2.0 , suggesting values up to $250 \mathrm{~mm}$ month $^{-1}\left(8 \mathrm{~mm} \mathrm{~d}^{-1}\right)$ in the Sudanian zone, with a strong correlation between interannual anomalies in $P$ and $E$. These results suggest that their $E$ and $P$ coupling model is too linear in nature. Another limitation in their approach might come from neglecting the impact of net surface radiation interannual variability.

[42] Brubaker et al. [1993] found even larger annual evapotranspiration with similar precipitation: $E=1464 \mathrm{~mm}$ $\mathrm{yr}^{-1}$ between $7.5^{\circ} \mathrm{N}$ and $15^{\circ} \mathrm{N}$ while $P=969 \mathrm{~mm} \mathrm{yr}^{-1}$, this led them to state that West Africa appears as a source region $(E-P>0)$, but they also pointed to the likeliness of considerable errors affecting their estimate. Most of the differences with the present study occur in the July-September (JAS) period: the MFD estimates differ by more than $100 \mathrm{~mm}$ 
month $^{-1}$, and $E$ estimates by more than $125 \mathrm{~mm}$ month $^{-1}$ $(150 \%)$, while $P$ estimates agree within $20 \mathrm{~mm}$ month $^{-1}$. They estimate moisture flux divergence (MFD $>0$ ) during the rainy season and, since they derived $E$ as a residual, overestimate $E$ in JAS. Moreover, the impact of either too strong $E$ or MFD $>0$ leads to an overestimation of their recycling index.

[43] Using a similar approach, Cadet and Nnoli [1987] estimate $E$ as a residual and find also too large values (around $10 \mathrm{~mm} \mathrm{~d}^{-1}$ ) in the Sudanian zone in JAS. More recent studies using NWP model simulations found contrasting results. Gong and Eltahir [1996] report $E$ peaking in JAS at $120 \mathrm{~mm} \mathrm{month}^{-1}$ over $5^{\circ} \mathrm{N}-15^{\circ} \mathrm{N}$ (30 mm month ${ }^{-1}$ too strong compared to ours), while their $P$ estimate is very close to ours (within $10 \mathrm{~mm}$ month $^{-1}$ ). Fontaine et al. [2003] report $E$ values too small in the Sahel, along with $E-P>0$ there, and $E$ too strong in the Sudano-Guinean zones, but with $E-P<0$ during JAS. Roads et al. [2002] report $E=2.28 \mathrm{~mm} \mathrm{~d}^{-1}$ $\left(832 \mathrm{~mm} \mathrm{yr}^{-1}\right)$ and $P=2.36 \mathrm{~mm} \mathrm{~d}^{-1}\left(861 \mathrm{~mm} \mathrm{yr}^{-1}\right)$, i.e., $E-P \sim 0$ over $5^{\circ} \mathrm{N}-15^{\circ} \mathrm{N}$. They also mention a runoff estimate from GRDC of $0.43 \mathrm{~mm} \mathrm{~d}^{-1}\left(157 \mathrm{~mm} \mathrm{yr}^{-1}\right)$ which is much more in line with the present LSM estimates. Interestingly, the description of the seasonal cycle of MFD from this group of studies, including also Zheng and Eltahir [1998], is in qualitative agreement with the present results. They support the idea that the rainy season is associated with moisture convergence and the dry season with moisture divergence. Fontaine et al. [2003] report similar results over whole West Africa, but they find a net moisture flux divergence on annual mean over the Sahel due to strong divergent flow in the midlevels.

\subsection{Interannual Variability}

[44] Few studies considered the links between interannual variability in $P$ and other water budget terms. Nicholson et al. [1997] showed that $E$ and runoff are positively correlated with annual mean precipitation. Eltahir and Gong [1996] and Fontaine et al. [2002] show that wetter seasons are associated with increased meridional gradient in entropy or moist static energy at surface which can be due to colder SST in the Gulf of Guinea and/or drier soil in the Sudan-Sahel before the rainy season. Such a signal is suggested by the present study $(\Delta E, \Delta \mathrm{dPW}$, and $\triangle \mathrm{MFC}$ being all negatively correlated with $\triangle P 3$ months ahead in the SAH box).

[45] Studies investigating the link between interannual variability in $P$ and dynamical factors in the atmospheric circulation are more numerous. Kidson [1977] and Janicot [1992a, 1992b], but especially Fontaine et al. [1995], Long et al. [2000], and Grist and Nicholson [2001], showed that wetter years are associated with a stronger Tropical Easterly Jet (TEJ), a weaker African Easterly Jet (AEJ), and stronger southwesterly monsoon flow. Drier years and drought periods are characterized by opposite anomalies. These studies further [see also Nicholson, 2009] showed that anomalous years are associated with latitudinal displacements of the jets axes. The present findings agree qualitatively with these studies in the sense that a change in vertically integrated MFC is consistent with a change in moisture transport both in low levels and midlevels. For instance, coherent displacements of the moisture convergence band are observed and an increased MFC occurs over the Sahel in wet years. It may be due to an enhancement of the low-level moisture flux and a decrease of wind strength in the AEJ (the "main moisture artery" over West Africa according to Cadet and Nnoli [1987], which would be consistent with Fontaine et al. [2003].

\section{Conclusion}

[46] This study investigated the water cycle over West Africa with the help of a new hybrid water budget data set developed within the framework of AMMA and covering the years 2002 to 2007 . This data set was elaborated from satellite products jointly used with land surface model outputs. It is expected to provide an advanced, more accurate characterization of the water budget over West Africa compared to the few previously used data sets. The annual mean, seasonal cycle and interannual variability of the water cycle has been presented and discussed. Couplings between budget terms have also been highlighted. New and quantitative answers to a number of questions about the West African Monsoon water cycle have been proposed.

[47] On annual mean, West Africa is shown to be a moisture source region for the surface, or equivalently a sink region for the atmosphere. Our results contrast with a number of previous studies which estimated much higher evapotranspiration rates. Surface evapotranspiration and moisture flux convergence appear to both play an important role in the mean seasonal cycle. Results also suggest that recycling may play a stronger role in the Sahel. Evidence is given that moisture flux convergence plays a dominant role in determining the amount of rainfall at regional scale. Fluctuations in moisture flux convergence appear significantly correlated with rainfall on a broad range of time scales, from daily to seasonal and interannual. The lack of consensus emerging from previous studies on these issues is apparently associated with differences in the various data sets used for the estimation of the water budget terms. The only real consensus found in previous studies is about the major role of large-scale atmospheric features such as the AEJ, the TEJ, and the lowlevel flow. Because of strong vertical wind shear [Grist and Nicholson, 2001; Fontaine et al., 2002; Nicholson, 2009] large uncertainties may remain in the vertically integrated MFD computations and hence impact the water budget. In the present study, the vertically integrated MFD is estimated as a residual, hence avoiding the direct computation of vertical integrals. Vertically resolved budgets would be further useful to assess the weight of the different atmospheric layers in the overall budget. This would also help studying the origins of rainfall (continental versus oceanic), the role of the atmospheric flow (AEJ versus the southerly and northerly lowlevel flow) in the water budget. More recent NWP models now offer high horizontal and vertical resolution and benefit from improved physics and assimilation systems. It thus appears valuable to reassess such products for regional-scale water budget studies. This is the objective of a companion paper. There, the performance of various NWP models in simulating and analyzing water budget terms over West Africa are evaluated with the hybrid data set and the new results presented here.

\section{Appendix A}

[48] Figures A1 and A2 compare monthly mean and temporal standard deviation of precipitation products, evapo- 
(a) $\mathbf{P}$
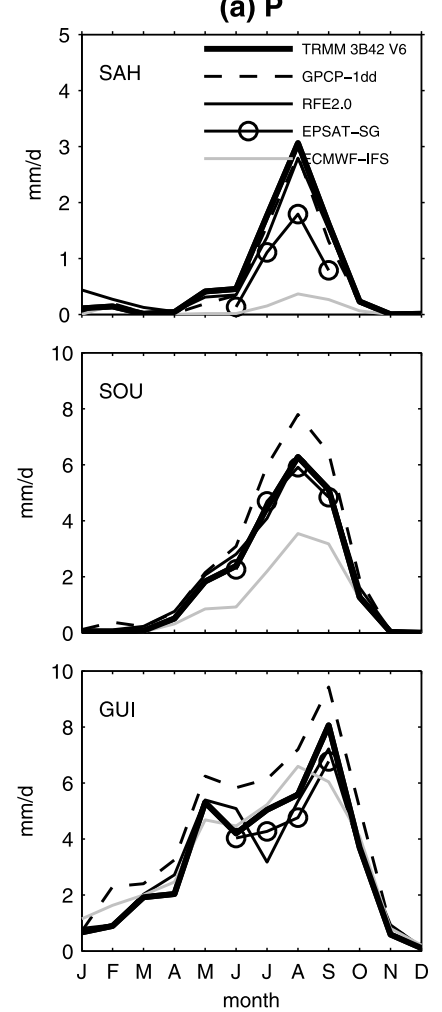

(b) $\mathrm{E}$
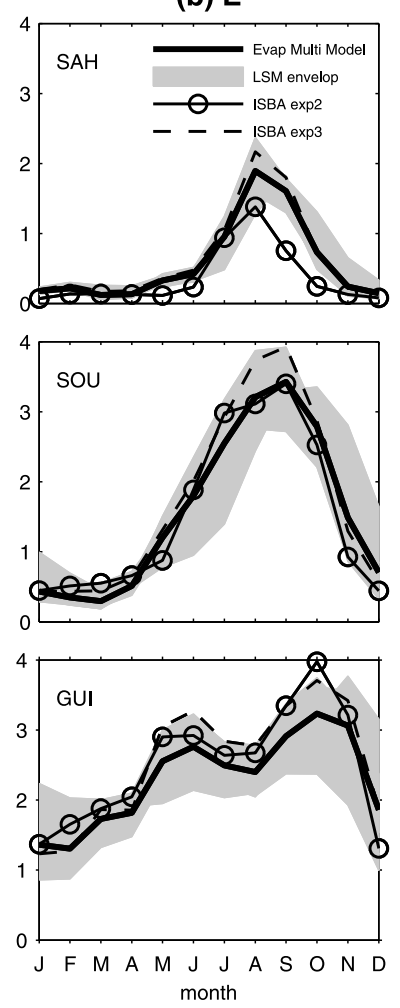

(c) MFD
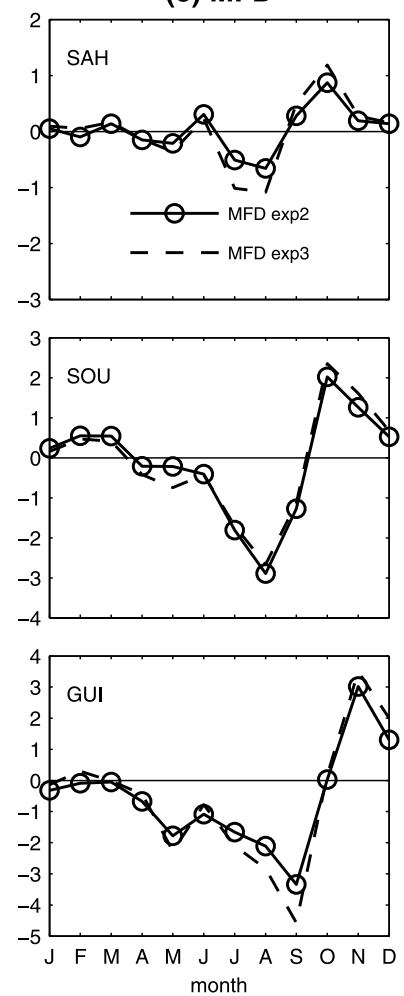

(d) dPW
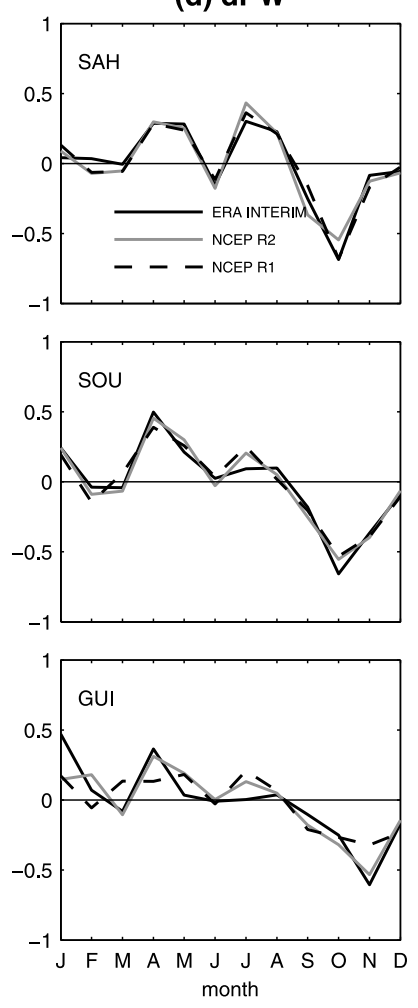

Figure A1. Monthly mean time series of (a) precipitation estimates (satellite products and ECMWIF-IFS forecast), (b) evapotranspiration estimates from nine ALMIP land surface model (shading), multimodel average (bold line), and ISBA LSM used in ALMIP experiments 2 and 3 (dashed line and line with circles); (c) moisture flux divergence estimates derived from ISBA LSM experiments 2 and 3; and (d) precipitable water tendency from three numerical weather prediction model reanalyses (ERA-Interim, NCEP-U.S. DOE (R2), and NCEP-NCAR (R1)). All quantities are spatial averages in the three domains indicated in Figure 1 for the year 2006. Units are $\mathrm{mm} \mathrm{d}^{-1}$. 
(a) $\mathbf{P}$
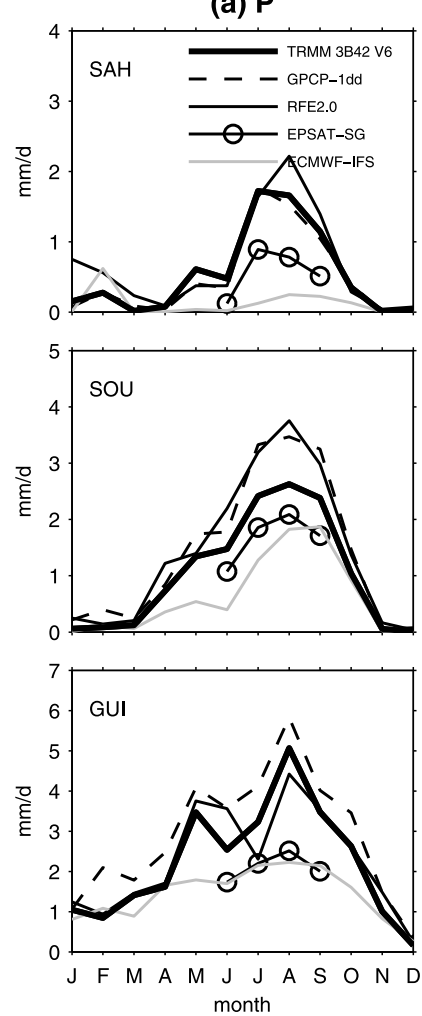

(b) $E$
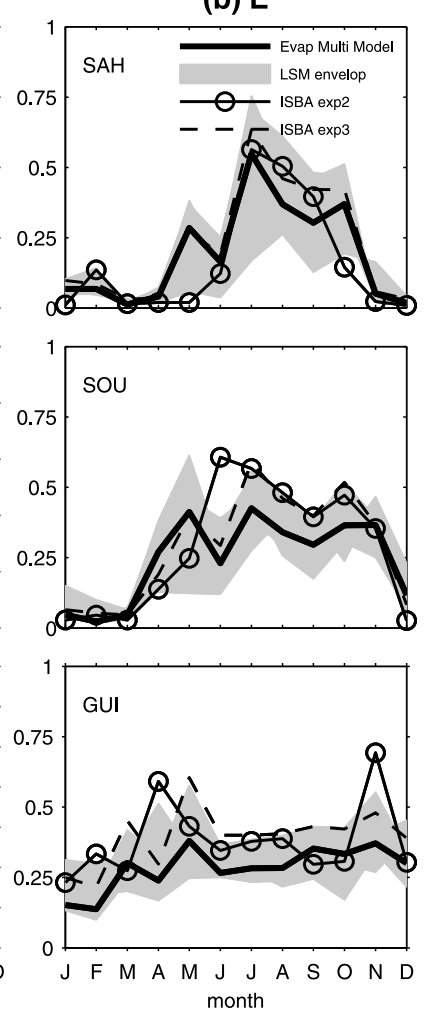

(c) MFD
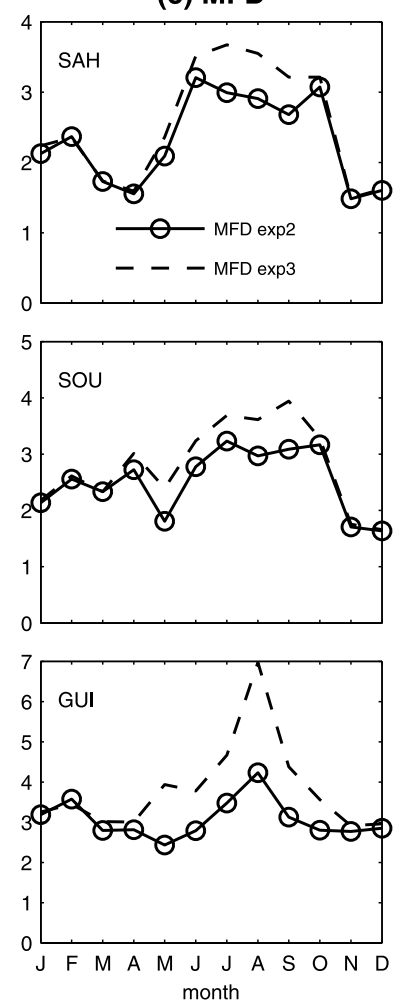

(d) dPW
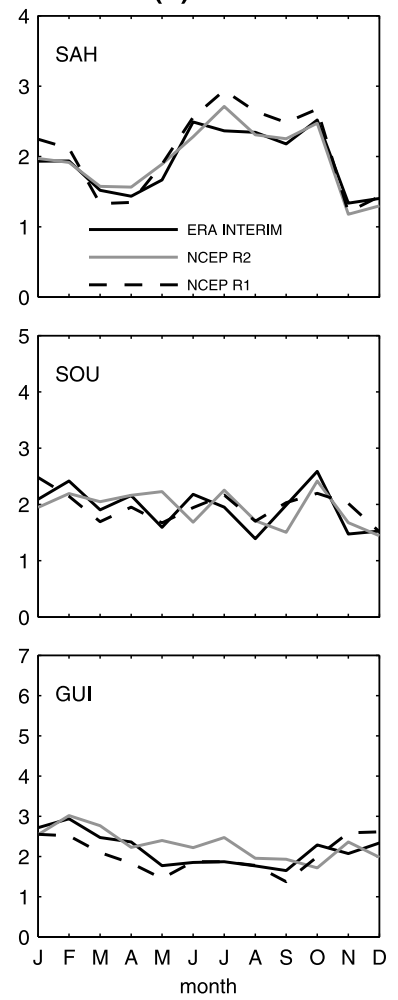

Figure A2. Similar to Figure A1, but for standard deviation of daily mean (i.e., day-to-day variability). 

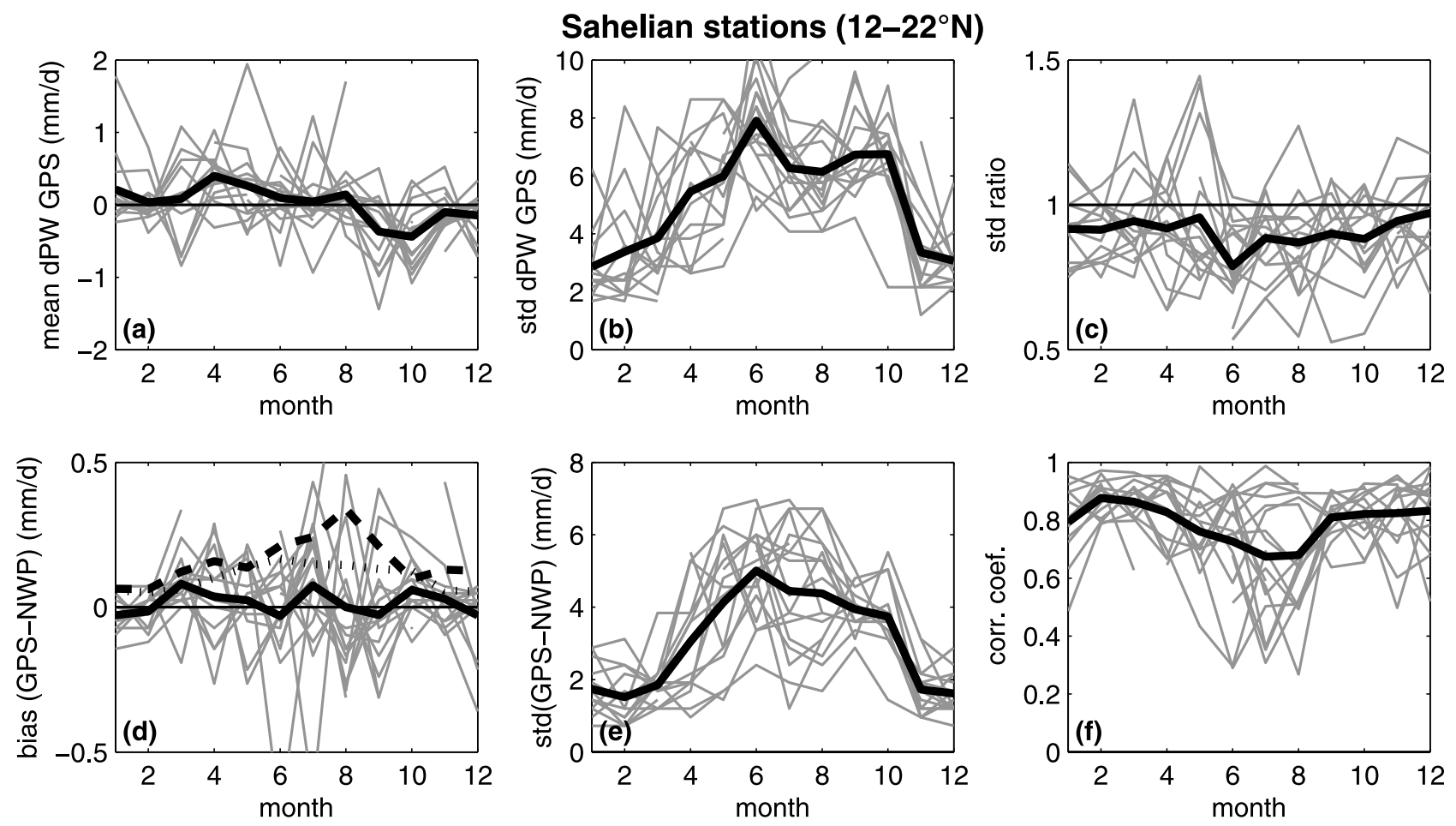

Figure A3. Evaluation of daily dPW from GPS observations and ERA-Interim analysis at six GPS sites (Ouagadougou, $12.5^{\circ} \mathrm{N}$; Niamey, $13.5^{\circ} \mathrm{N}$; Dakar, $14.7^{\circ} \mathrm{N}$; Gao, $16.3^{\circ} \mathrm{N}$; Tombouctou, $16.7^{\circ} \mathrm{N}$; and Tamanrasset, $22.8^{\circ} \mathrm{N}$ ), monthly averages over years 2005-2008. The thin shaded lines show the results for all stations and all years; the bold lines show the average for each month. (a) Monthly mean dPWGPS. (b) Standard deviation of daily dPWGPS. (c) Standard deviation ratio of dPWERA-Interim over dPWGPS. (d) Monthly mean bias (dPWERA-Interim-dPWGPS), standard deviation of the monthly mean bias (dashed line), and standard deviation of the daily model-GPS difference divided by the number of days in each month (dotted line). (e) Standard deviation of dPWERA-Interim-dPWGPS. (f) Linear correlation coefficient between dPWERA-Interim over dPWGPS.

transpiration, from ALMIP experiments 2 and 3 , and corresponding MFD estimates and dPW from three NWP reanalysis products, respectively. The data are averaged over West Africa in the three boxes used in the study, but limited here to year 2006.

[49] The comparison of several precipitation products provides information on the uncertainty one can expect when choosing one specific product. Here, EPSAT-SG and TRMM 3B42 (which are used in ALMIP experiments 2 and 3) are compared to two other widely used products: CPC/RFE. 2 [Love et al., 2004] and GPCP-1dd [Huffman et al., 2001]. Although the seasonal variations is well captured by all four products, differences between them can reach $2 \mathrm{~mm} \mathrm{~d}^{-1}$ for monthly averages (Figure A1a) and $3 \mathrm{~mm} \mathrm{~d}^{-1}$ for submonthly variability (Figure A2a) in the GUI box. The dispersion is also the strongest in this box. More to the north, precipitation estimates show better agreement. The GPCP estimate is the largest in term of mean and standard deviation over West Africa, while EPSAT-SG is the smallest. TRMM precipitation estimate lies on the average of the products considered here (both in term of mean and standard deviation). It also appears close to CPC/RFE2.0 monthly mean estimates. Overall, the agreement between the satellite products is at the level of 1-2 $\mathrm{mm} \mathrm{d}^{-1}$ for monthly averages and $1-3 \mathrm{~mm} \mathrm{~d}^{-1}$ for day-to-day variability. Figure Ala also shows the ECMWFIFS simulated precipitation used in ALMIP experiment 1 or 2 when EPSAT-SG was not available. In the SOU and SAH boxes, ECMWF-IFS significantly underestimates rainfall over West Africa, by $1-2 \mathrm{~mm} \mathrm{~d}^{-1}$ depending on the satellite product considered. This large bias associated with the discontinuity linked with the switch between ECMWF-IFS precipitation and EPSAT-SG twice a year seriously hampers the pertinence of experiment 2 for the present study (seasonal cycle and interannual variability).

[50] The dispersion of the nine LSMs (indicated by the shaded envelop in Figure A1b) around the multimodel average (thick line) is about $0.5-1 \mathrm{~mm} \mathrm{~d}^{-1}$ in the three boxes (dispersion being larger more to the south). The day-to-day variability of $E$ (Figure A2b) for the ensemble LSM simulations shows a dispersion with the multimodel estimate around $0.25 \mathrm{~mm} \mathrm{~d}^{-1}$. The impact on $E$ estimates of changing the precipitation forcing is illustrated comparing Interaction SolBiosphère-Atmosphère (ISBA [Noilhan and Planton, 1989]) simulations between experiments 2 and 3 . The monthly mean difference is smaller than $1 \mathrm{~mm} \mathrm{~d}^{-1}$ and is well correlated with the difference in the precipitation products used as forcing in these experiments (Figure Ala).

[51] Figure A1c shows the impact of the change in precipitation products on the hybrid MFD estimate. This impact is quite small for monthly average $\left(<0.2 \mathrm{~mm} \mathrm{~d}^{-1}\right.$ or $10 \%$ of MFD). The difference in day-to-day variability can be larger (especially during the summer in the GUI box) and is con- 

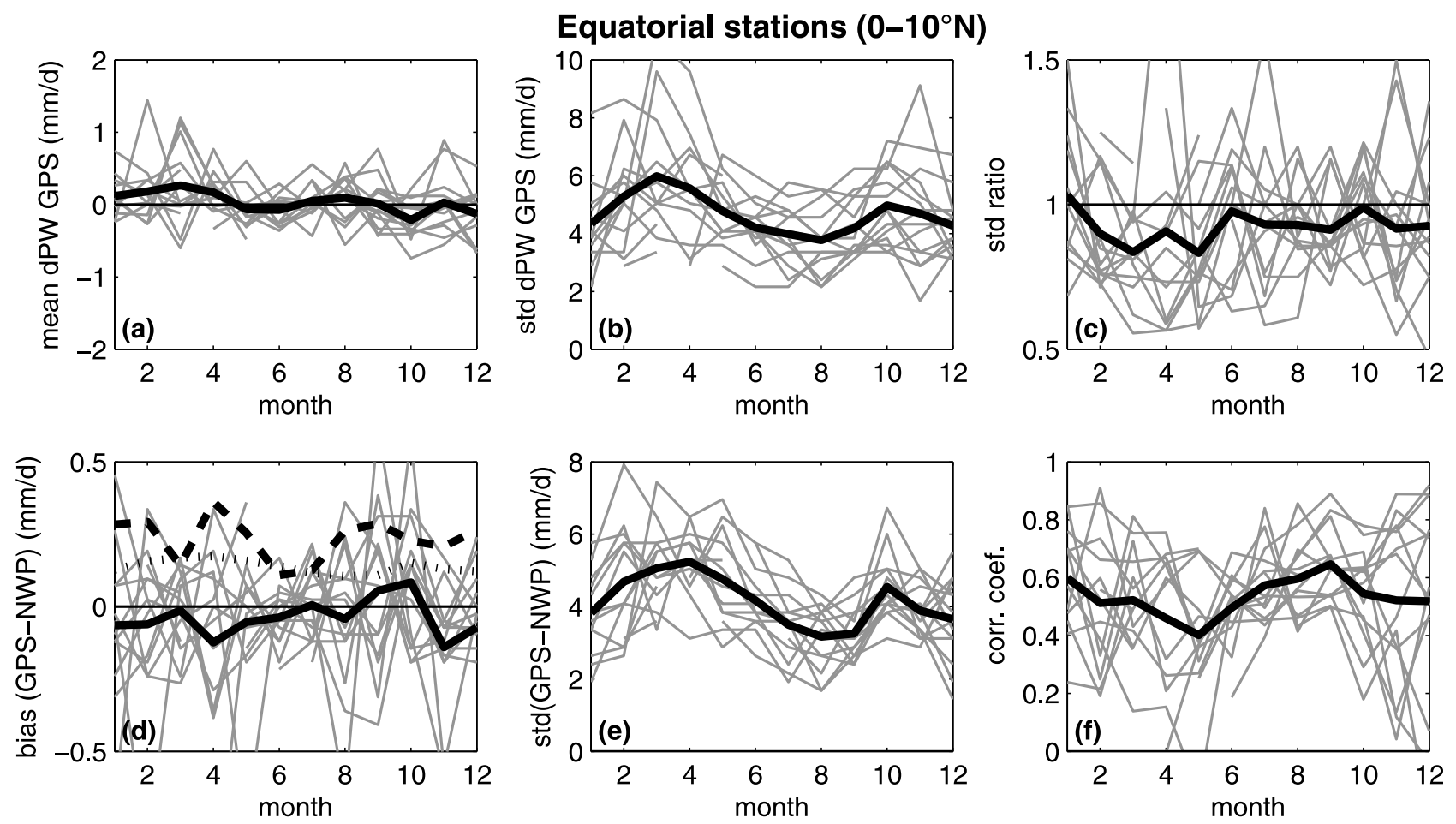

Figure A4. Similar to Figure A3, but at six Guinean and equatorial sites (Masuku, $-1.6^{\circ} \mathrm{N}$; Mbarara, $-0.6^{\circ} \mathrm{N}$; N’Koltang, $0.3^{\circ} \mathrm{N}$; Cotonou, $6.4^{\circ} \mathrm{N}$; Tamale, $9.6^{\circ} \mathrm{N}$; Djougou, $9.7^{\circ} \mathrm{N}$ ).

sistent with the difference seen in precipitation products variability (Figure A2a).

[52] Figure A1d compares dPW estimates extracted from three NWP model reanalyses: European Centre for MediumRange Weather Forecasts (ECMWF) Re-Analysis (ERA)Interim [Simmons et al., 2006], NCEP-DOE Reanalysis II [Kanamitsu et al., 2002] (referred to as NCEP R2), and NCEP-NCAR Reanalysis I [Kalnay et al., 1996] (referred as NCEP R1). First of all, one must notice that, for monthly means and spatial averages over $\sim 10^{6} \mathrm{~km}^{2}, \mathrm{dPW}_{\mathrm{NWP}}$ is small compared to $P$ and $E$ terms. So, this parameter is not critical at the monthly time scale but submonthly variability is shown to be more significant and is comparable to other terms fluctuations in term of amplitude (Figure A2). However, the agreement between the three reanalyses is quite good for both monthly average and day-to-day variability. This suggests that the choice of a particular NWP model is not of prime importance either. When considering smaller space scales, the accuracy of NWP models will, however, not be as accurate [Bock et al., 2007; Bock and Nuret, 2009]. The three reanalyses are further evaluated here with the help of PWV estimates derived from GPS observations [Bock et al., 2008].

[53] Figure A3 compares dPW estimates from GPS and ERA-Interim at six Sahelian sites. Figure A3a shows the monthly mean $\mathrm{dPW}_{\mathrm{GPS}}$. This term is small on average (black solid line), but the scatter (site to site or year to year) can exceed $1 \mathrm{~mm} \mathrm{~d}^{-1}$ locally. Figure A3d shows that the bias in the reanalysis (black solid line) is quite small at this scale and consistent with two different estimates of uncertainty: the standard deviation of the monthly mean bias (dashed line) and the standard deviation of daily model-GPS difference divided by the number of days in each month (dotted line). The standard deviation of daily $\mathrm{dPW}_{\mathrm{GPS}}$ (Figure A3b) reveals large variability during the monsoon season with peaks at the onset and retreat of the monsoon (June and October). This variability is weaker in the reanalysis as attested by the ratio of $\mathrm{dPW}_{\mathrm{NWP}}$ over $\mathrm{dPW}_{\mathrm{GPS}}$, which is smaller than one. The linear correlation coefficient between $\mathrm{dPW}_{\mathrm{NWP}}$ over $\mathrm{dPW}_{\mathrm{GPS}}$ is higher during the dry season than during the wet season (Figure A3f). Hence, the standard deviation of $\mathrm{dPW}_{\mathrm{NWP}}-$ $\mathrm{dPW}_{\mathrm{GPS}}$ (Figure A3f) is not small; it reaches $4-5 \mathrm{~mm} \mathrm{~d}^{-1}$ during the wet season. Figure A4 shows similar plots for equatorial and Guinean stations. The most significant differences with Sahelian stations are: maxima in dPW variability occurring in March and October (Figure A3b), i.e.,

Table A1. Statistics of Comparison Between Daily dPW From Three Numerical Weather Prediction Model Reanalyses With Regard to GPS Estimates, Averaged Over June-September ${ }^{\mathrm{a}}$

\begin{tabular}{lccccc}
\hline Model & $\begin{array}{c}\text { Std } \\
\text { GPS }\end{array}$ & $\begin{array}{c}\text { Std } \\
\text { Ratio }\end{array}$ & $\begin{array}{c}\text { Monthly } \\
\text { Bias Error }\end{array}$ & $\begin{array}{c}\text { Std } \\
\text { (NWP-GPS) }\end{array}$ & Correlation \\
\hline \multicolumn{5}{c}{ Sahelian Sites } \\
ERAI & 6.76 & 0.86 & $0.15-0.25$ & 4.45 & 0.72 \\
NCEP1 & 6.76 & 0.75 & $0.19-0.33$ & 5.64 & 0.55 \\
NCEP2 & 6.76 & 0.78 & $0.21-0.35$ & 6.23 & 0.45 \\
& & \multicolumn{7}{c}{ Equatorial and Guinean Sites } \\
ERAI & 4.04 & 0.94 & $0.12-0.20$ & 3.52 & 0.58 \\
NCEP1 & 4.86 & 0.73 & $0.15-0.24$ & 4.57 & 0.42 \\
NCEP2 & 4.86 & 1.06 & $0.19-0.35$ & 5.64 & 0.35 \\
\hline
\end{tabular}

${ }^{\mathrm{a}} \mathrm{Std}$ GPS is the standard deviation of daily $\mathrm{dPW}\left(\mathrm{mm} \mathrm{d}^{-1}\right)$, Std ratio is the ratio of the numerical weather prediction (NWP) model dPW standard deviation to the GPS standard deviation, monthly bias error is computed from two different uncertainty estimates $\left(\mathrm{mm} \mathrm{d}^{-1}\right)$, Std (NWP-GPS) is the standard deviation of difference $\left(\mathrm{mm} \mathrm{d}^{-1}\right)$, and correlation is the linear correlation coefficient between $\mathrm{dPW}_{\mathrm{GPS}}$ and $\mathrm{dPW}_{\mathrm{NWP}}$. See text for further details. 
during the month when the ITCZ is moving across the stations; and overall smaller agreement between model and GPS (Figures A3e and A3f). Table A1 summarizes the results for ERA-Interim as well as the two NCEP reanalyses, on average over June-September. Overall, ERA-Interim shows better agreement with GPS than the NCEP reanalyses, but this might be due to differences in representativeness (the variance of daily dPW decreases at larger spatial scales). Most importantly here, the uncertainty in local (grid point) scale, monthly mean dPW from the reanalyses ranges between 0.15 and $0.35 \mathrm{~mm} \mathrm{~d}^{-1}$, over West Africa.

[54] Acknowledgments. On the basis of a French initiative, AMMA was built by an international scientific group and is currently funded by a large number of agencies, especially from France, the United Kingdom, the United States, and Africa. It has been the beneficiary of a major financial contribution from the European Community's Sixth Framework Research Programme. Detailed information on scientific coordination and funding is available on the AMMA International Web site (http://www.ammainternational.org/). We thank S. Cloche for providing the satellite and NWP model products.

\section{References}

Ali, A., and T. Lebel (2009), The Sahelian standardized rainfall index revisited, Int. J. Climatol., 29, 1705-1714, doi:10.1002/joc.1832.

Barnes, G. M., and K. Sieckman (1984), The environment of fast- and slow-moving tropical mesoscale convective cloud lines, Mon. Weather Rev., 112, 1782-1794, doi:10.1175/1520-0493(1984)112<1782: TEOFAS $>2.0 . \mathrm{CO} ; 2$.

Berges, J. C., I. Jobard, F. Chopin, and R. Roca (2010), EPSAT-SG: A satellite method for precipitation estimation; its concepts and implementation for the AMMA experiment, Ann. Geophys., 28, 289-308, doi:10.5194/angeo-28-289-2010.

Bielli, S., and R. Roca (2009), Scale decomposition of atmospheric water budget over West Africa during the monsoon 2006 from NCEP/GFS analyses, Clim. Dyn., 35, 143-157, doi:10.1007/s00382-009-0597-5.

Bock, O., and M. Nuret (2009), Verification of NWP model analyses and radiosonde humidity data with GPS precipitable water vapor estimates during AMMA, Weather Forecast., 24, 1085-1101, doi:10.1175/ 2009WAF2222239.1

Bock, O., M.-N. Bouin, A. Walpersdorf, J. P. Lafore, S. Janicot, F. Guichard, and A. Agusti-Panareda (2007), Comparison of ground-based GPS precipitable water vapour to independent observations and numerical weather prediction model reanalyses over Africa, Q. J. R. Meteorol. Soc., 133, 2011-2027, doi:10.1002/qj.185.

Bock, O., et al. (2008), West African Monsoon observed with groundbased GPS receivers during African Monsoon Multidisciplinary Analysis (AMMA), J. Geophys. Res., 113, D21105, doi:10.1029/2008JD010327.

Boone, A., et al. (2009), The AMMA Land Surface Model Intercomparison Project (ALMIP), Bull. Am. Meteorol. Soc., 90, 1865-1880, doi:10.1175/ 2009BAMS2786.1.

Brubaker, K. L., D. Entekhabi, and P. S. Eagleson (1993), Estimation of continental precipitation recycling, J. Clim., 6, 1077-1089, doi:10.1175/ 1520-0442(1993)006<1077:EOCPR >2.0.CO;2.

Cadet, D. L., and O. Nnoli (1987), Water vapour transport over Africa and the Atlantic Ocean during summer 1979, Q. J. R. Meteorol. Soc., 113, 581-602, doi:10.1002/qj.49711347609.

Caniaux, G., J. L. Redelsperger, and J. P. Lafore (1994), A numerical study of the stratiform region of a fast-moving squall line. Part I: General description and water and heat budgets, J. Atmos. Sci., 51, 2046-2074, doi:10.1175/1520-0469(1994)051<2046:ANSOTS >2.0.CO;2.

Charney, J. G. (1975), Dynamics of deserts and drought in the Sahel, Q. J. R. Meteorol. Soc., 101, 193-202, doi:10.1002/qj.49710142802.

Diedhiou, A., S. Janicot, A. Viltard, P. De Felice, and H. Laurent (1999), Easterly wave regimes and associated convection over West Africa and the tropical Atlantic: Results from the NCEP/NCAR and ECMWF reanalyses, Clim. Dyn., 15, 795-822, doi:10.1007/s003820050316.

Diongue, A., J. P. Lafore, J. L. Redelsperger, and R. Roca (2002), Numerical study of a Sahelian synoptic weather system: Initiation and mature stages of convection and its interactions with the large-scale dynamics, Q. J. R. Meteorol. Soc., 128, 1899-1927, doi:10.1256/ 003590002320603467.
Dirmeyer, P. A., R. D. Koster, and Z. Guo (2006), Do global models properly represent the feedback between land and atmosphere?, J. Hydrometeorol., 7, 1177-1198, doi:10.1175/JHM532.1.

Douville, H., F. Chauvin, and H. Broqua (2001), Influence of soil moisture on the Asian and African monsoons. Part I: Mean monsoon and daily precipitation, J. Clim., 14, 2381-2403, doi:10.1175/1520-0442(2001) $014<2381$ :IOSMOT $>2.0$.CO;2.

Ebisuzaki, W. (1997), A method to estimate the statistical significance of a correlation when the data are serially correlated, J. Clim., 10, 2147-2153, doi:10.1175/1520-0442(1997)010<2147:AMTETS>2.0.CO;2.

Eltahir, E. A. B., and C. Gong (1996), Dynamics of wet and dry years in West Africa, J. Clim., 9, 1030-1042, doi:10.1175/1520-0442(1996) 009<1030:DOWADY $>2.0$. CO;2.

Fink, A. H., and A. Reiner (2003), Spatio-temporal variability of the relation between African easterly waves and West African squall lines in 1998 and 1999, J. Geophys. Res., 108(D11), 4332, doi:10.1029/ 2002JD002816.

Fontaine, B., S. Janicot, and V. Moron (1995), Rainfall anomaly patterns and wind field signals over West Africa in August (1958-1989), J. Clim., 8, 1503-1510, doi:10.1175/1520-0442(1995)008<1503:RAPAWF $>2.0$. $\mathrm{CO} ; 2$.

Fontaine, B., N. Philippon, S. Trzaska, and P. Roucou (2002), Spring to summer changes in the West African Monsoon through NCEP/NCAR reanalyses (1968-1998), J. Geophys. Res., 107(D14), 4186, doi:10.1029/ 2001JD000834.

Fontaine, B., P. Roucou, and S. Trzaska (2003), Atmospheric water cycle and moisture fluxes in the West African Monsoon: Mean annual cycles and relationship using NCEP/NCAR reanalysis, Geophys. Res. Lett., 30(3), 1117, doi:10.1029/2002GL015834.

Geiger, B., C. Meurey, D. Lajas, L. Franchist'guy, D. Carrer, and J.-L. Roujean (2008), Near real-time provision of downwelling shortwave radiation estimates derived from satellite observations, Meteorol. Appl., 15, 411-420, doi:10.1002/met.84.

Giannini, A., R. Saravanan, and P. Chang (2003), Oceanic forcing of Sahel rainfall on interannual to interdecadal time scales, Science, 302, 1027-1030, doi:10.1126/science.1089357.

Gong, C., and E. A. B. Eltahir (1996), Sources of moisture for rainfall in West Africa, Water Resour. Res., 32, 3115-3121, doi:10.1029/ 96WR01940.

Grist, J. P., and S. E. Nicholson (2001), A study of the dynamics factors influencing the rainfall variability in the West African Sahel, J. Clim., 14, 1337-1359, doi:10.1175/1520-0442(2001)014<1337:ASOTDF $>2.0$. $\mathrm{CO} ; 2$.

Guichard, F., J.-P. Lafore, and J.-L. Redelsperger (1997), Thermodynamical impact and internal structure of a tropical convective cloud system, O. J. R. Meteorol. Soc., 123, 2297-2324, doi:10.1002/qj.49712354408.

Guichard, F., L. Kergoat, E. Mougin, F. Timouk, F. Baup, P. Hiernaux, and F. Lavenu (2009), Surface thermodynamics and radiative budget in the Sahelian Gourma: Seasonal and diurnal cycles, J. Hydrol., 375, 161-177, doi:10.1016/j.jhydrol.2008.09.007.

Huffman, G. J., R. F. Adler, M. M. Morrissey, D. T. Bolvin, S. Curtis, R. Joyce, B. McGavock, and J. Susskind (2001), Global precipitation at one-degree daily resolution from multisatellite observations, J. Hydrometeorol., 2, 36-50.

Huffman, G. J., et al. (2007), The TRMM Multisatellite Precipitation Analysis (TMPA): Quasi-global, multiyear, combined-sensor precipitation estimates at fine scales, J. Hydrometeorol., 8, 38-55, doi:10.1175/ JHM560.1.

Janicot, S. (1992a), Spatio-temporal variability of West African rainfall. Part I: Regionalizations and typings, J. Clim., 5, 489-498, doi:10.1175/ 1520-0442(1992)005<0489:SVOWAR>2.0.CO;2.

Janicot, S. (1992b), Spatio-temporal variability of West African rainfall. Part II: Associated surface and airmass characteristics, J. Clim., 5, 499-511, doi:10.1175/1520-0442(1992)005<0499: SVOWAR $>2.0$. $\mathrm{CO} ; 2$.

Janicot, S., A. Harzallah, B. Fontaine, and V. Moron (1998), West African Monsoon dynamics and eastern equatorial Atlantic and Pacific SST anomalies (1970-1988), J. Clim., 11, 1874-1882, doi:10.1175/15200442(1998)011<1874:WAMDAE $>2.0 . C O ; 2$.

Janicot, S., et al. (2008), Large-scale overview of the summer monsoon over West Africa during the AMMA field experiment in 2006, Ann. Geophys., 26, 2569-2595, doi:10.5194/angeo-26-2569-2008.

Kalnay, E., et al. (1996), The NCEP/NCAR 40-Year Reanalysis Project, Bull. Am. Meteorol. Soc., 77, 437-471, doi:10.1175/1520-0477(1996) 077<0437:TNYRP $>2.0$. CO;2.

Kanamitsu, M., W. Ebisuzaki, J. Woollen, S.-K. Yang, J. J. Hnilo, M. Fiorino, and A. N. D. G. L. Potter (2002), NCEP-DOE AMIP-II Reanalysis 
(R-2), Bull. Am. Meteorol. Soc., 83, 1631-1643, doi:10.1175/BAMS-8311-1631(2002)083<1631:NAR>2.3.CO;2.

Kidson, J. W. (1977), African rainfall and its relation to the upper air circulation, $O$. J. R. Meteorol. Soc., 103, 441-456, doi:10.1002/ qj. 49710343705 .

Koster, R. D., et al. (2004), Regions of strong coupling between soil moisture and precipitation, Science, 305, 1138-1140, doi:10.1126/ science. 1100217.

Laing, A. G., and J. M. Fritsch (1993), Mesoscale convective complexes in Africa, Mon. Weather Rev., 121, 2254-2263, doi:10.1175/15200493(1993)121<2254:MCCIA>2.0.CO;2.

Lamb, P. J. (1983), West African water vapor variations between recent contrasting sub-Saharan rainy seasons, Tellus, Ser. A, 35, 198-212, doi:10.1111/j.1600-0870.1983.tb00197.x.

Le Barbé, L., T. Lebel, and D. Tapsoba (2002), Rainfall variability in West Africa during the years 1950-90, J. Clim., 15, 187-202, doi:10.1175/ 1520-0442(2002)015<0187:RVIWAD $>2.0 . C O ; 2$.

Lebel, T., J. D. Taupin, and N. D'Amato (1997), Rainfall monitoring during HAPEX-Sahel. 1. General rainfall conditions and climatology, J. Hydrol., 188-189, 74-96, doi:10.1016/S0022-1694(96)03155-1.

Lebel, T., A. Diedhiou, and H. Laurent (2003), Seasonal cycle and interannual variability of the Sahelian rainfall at hydrological scales, J. Geophys. Res., 108(D8), 8389, doi:10.1029/2001JD001580.

Long, M., D. Entekhabi, and S. E. Nicholson (2000), Interannual variability in rainfall, water vapor flux and vertical motion over West Africa, J. Clim., 13, 3827-3841, doi:10.1175/1520-0442(2000)013<3827: IVIRWV $>2.0 . \mathrm{CO} ; 2$

Lotsch, A., M. A. Friedl, B. T. Anderson, and C. J. Tucker (2003), Coupled vegetation-precipitation variability observed from satellite and climate records, Geophys. Res. Lett., 30(14), 1774, doi:10.1029/2003GL017506.

Love, T. B., V. Kumar, P. Xie, and W. Thiaw (2004), A 20-year daily Africa precipitation climatology using satellite and gauge data, paper presented at the 84th Annual Meeting, Conference on Applied Climatology, Am. Meteorol. Soc., Seattle, Wash.

Masson, V., J.-L. Champeaux, F. Chauvin, C. Meriguet, and R. Lacaze (2003), A global database of land surface parameters at $1-\mathrm{km}$ resolution in meteorological and climate models, J. Clim., 16, 1261-1282, doi:10.1175/1520-0442(2003)16<1261:AGDOLS>2.0.CO;2.

Mathon, V., H. Laurent, and T. Lebel (2002), Mesoscale convective system rainfall in the Sahel, J. Appl. Meteorol., 41, 1081-1092, doi:10.1175/ 1520-0450(2002)041<1081:MCSRIT >2.0.CO;2.

Matthews, A. (2004), Intraseasonal variability over tropical Africa during northern summer, J. Clim., 17, 2427-2440, doi:10.1175/15200442(2004)017<2427:IVOTAD>2.0.CO;2.

Meynadier, R., O. Bock, S. Gervois, F. Guichard, J.-L. Redelsperger, A. Agustíi-Panareda, and A. Beljaars (2010), West African Monsoon water cycle: 2. Assessment of numerical weather prediction water budgets, J. Geophys. Res., 115, D19107, doi:10.1029/2009JD013919.

Mo, K. C., and R. W. Higgins (1996), Large-scale atmospheric moisture transport as evaluated in the NCEP/NCAR and the NASA/DAO reanalyses, J. Clim., 9, 1531-1545, doi:10.1175/1520-0442(1996)009<1531: LSAMTA $>2.0 . \mathrm{CO} ; 2$.

Mounier, F., S. Janicot, and G. N. Kiladis (2008), The West African Monsoon dynamics. Part III: The quasi-biweekly zonal dipole, J. Clim. 21, 1911-1928, doi:10.1175/2007JCLI1706.1.

Nicholson, S. E. (1981), Rainfall and atmospheric circulation during drought periods and wetter years in West Africa, Mon. Weather Rev., 109, 2191-2208, doi:10.1175/1520-0493(1981)109<2191:RAACDD $>2.0$ $\mathrm{CO} ; 2$.

Nicholson, S. E. (2009), On the factors modulating the intensity of the tropical rainbelt of West Africa, Int. J. Climatol., 29, 673-689, doi:10.1002 joc. 1702 .

Nicholson, S. E., M. L. Davenport, and A. R. Malo (1990), A comparison of the vegetation response to rainfall in the Sahel and East Africa, using normalized difference vegetation index from NOAA AVHRR, Clim. Change, 17, 209-241, doi:10.1007/BF00138369.

Nicholson, S. E., J. Kim, M. B. Ba, and A. R. Lare (1997), The mean surface water balance over Africa and its interannual variability, J. Clim., 10, 2981-3002, doi:10.1175/1520-0442(1997)010<2981: TMSWBO $>2.0 . \mathrm{CO} ; 2$.

Nicholson, S. E., et al. (2003), Validation of TRMM and other rainfall estimates with a high-density gauge dataset for West Africa. Part II: Validation of TRMM rainfall products, J. Appl. Meteorol., 42, 13551368, doi:10.1175/1520-0450(2003)042<1355:VOTAOR >2.0.CO;2.

Nieto, R., L. Gimeno, and R. M. Trigo (2006), A Lagrangian identification of major sources of Sahel moisture, Geophys. Res. Lett., 33, L18707, doi:10.1029/2006GL027232.
Noilhan, J., and S. Planton (1989), A simple parameterization of land surface processes for meteorological models, Mon. Weather Rev., 117, 536-549.

Oort, A. H. (1983), Global atmospheric circulation statistics, 1958-1973, NOAA Prof. Pap. 14, U.S. Govt. Print. Office, Washington, D. C.

Peixoto, J. P., and A. H. Oort (1983), The atmospheric branch of the hydrological cycle and climate, in Variations in the Global Water Budget, edited by M. Beran and R. Ratcliffe, pp. 5-65, D. Reidel, Norwell, Mass.

Polcher, J. (1995), Sensitivity of tropical convection to land surface processes, J. Atmos. Sci., 52, 3143-3161, doi:10.1175/1520-0469(1995)052< 3143:SOTCTL $>2.0 . \mathrm{CO} ; 2$

Rasmusson, E. M., and K. C. Mo (1996), Large-scale atmospheric moisture cycling as evaluated from NMC global analysis and forecast products, J. Clim., 9, 3276-3297, doi:10.1175/1520-0442(1996)009<3276: LSAMCA $>2.0 . \mathrm{CO} ; 2$

Redelsperger, J.-L., A. Diongue, A. Diedhiou, J.-P. Ceron, M. Diop, J.-F. Gueremy, and J.-P. Lafore (2002), Multi-scale description of a Sahelian synoptic weather system representative of the West African Monsoon, Q. J. R. Meteorol. Soc., 128, 1229-1257, doi:10.1256/ 003590002320373274

Redelsperger, J.-L., C. Thorncroft, A. Diedhiou, T. Lebel, D. J. Parker, and J. Polcher (2006), African Monsoon Multidisciplinary Analysis (AMMA): An international research project and field campaign, Bull. Am. Meteorol. Soc., 87, 1739-1746, doi:10.1175/BAMS-87-12-1739.

Roads, J., and A. Betts (2000), NCEP-NCAR and ECMWF reanalysis surface water and energy budgets for the Mississippi River basin, J. Hydrometeorol., 1, 88-94, doi:10.1175/1525-7541(2000)001<0088. NNAERS $>2.0 . \mathrm{CO} ; 2$

Roads, J., M. Kanamitsu, and R. Stewart (2002), CSE water and energy budgets in the NCEP-DOE Reanalysis II, J. Hydrometeorol., 3, 227248, doi:10.1175/1525-7541(2002)003<0227:CWAEBI >2.0.CO;2.

Roca, R., P. Chambon, I. Jobard, P. E. Kirstetter, M. Gosset, and J. C. Bergès (2010), Comparing satellite and surface rainfall products over West Africa at meteorologically relevant scales during the AMMA campaign using error estimates, J. Appl. Meteorol. Climatol., 49, 715-731, doi:10.1175/2009JAMC2318.1.

Rowell, C., K. Folland, K. Maskell, and M. N. Ward (1995), Variability of summer rainfall over tropical North Africa (1906-92): Observations and modeling, Q. J. R. Meteorol. Soc., 121, 669-704, doi:10.1002/ qj. 49712152311.

Ruane, A. C., and J. O. Roads (2008), Dominant balances and exchanges of the atmospheric water cycle in the Reanalysis-2 at diurnal, annual, and intraseasonal time scales, J. Clim., 21, 3951-3966, doi:10.1175/ 2007JCLI2015.1.

Samain, O., L. Kergoat, P. Hiernaux, F. Guichard, E. Mougin, F. Timouk, and F. Lavenu (2008), Analysis of the in situ and MODIS albedo variability at multiple time scales in the Sahel, J. Geophys. Res., 113, D14119, doi:10.1029/2007JD009174.

Saux-Picart, S., et al. (2009), Water and energy budgets simulation over the AMMA-Niger super-site spatially constrained with remote sensing data, J. Hydrol., 375, 287-295, doi:10.1016/j.jhydrol.2008.12.023.

Shea, D. J. (1986), Climatological atlas: 1950-1979, surface air temperature, precipitation, sea-level pressure, and sea-surface temperature $\left(45^{\circ} \mathrm{S}-90^{\circ} \mathrm{N}\right)$, Rep. $T N-269+S T R, 220$ pp., Natl. Cent. for Atmos. Res. Boulder, Colo.

Shinoda, M. (1995), Seasonal phase lag between rainfall and vegetation activity in tropical Africa as revealed by NOAA satellite data, Int. J. Climatol., 15, 639-656, doi:10.1002/joc.3370150605.

Simmons, A., S. Uppala, D. Dee, and S. Kobayashi (2006), ERA-Interim: ECMWF reanalysis products from 1989 onwards, ECMWF Newsl., 110, $25-35$.

Slingo, A., H. E. White, N. A. Bharmal, and G. J. Robinson (2009), Overview of observations from the RADAGAST experiment in Niamey, Niger: 2. Radiative fluxes and divergences, J. Geophys. Res., 114, D00E04, doi:10.1029/2008JD010497.

Sultan, B., and S. Janicot (2000), Abrupt shift of the ITCZ over West Africa, Geophys. Res. Lett., 27, 3353-3356, doi:10.1029/1999GL011285.

Sultan, B., S. Janicot, and A. Diedhiou (2003), West African Monsoon dynamics. Part I: Documentation of intraseasonal variability, J. Clim., 16, 3389-3406, doi:10.1175/1520-0442(2003)016<3389:TWAMDP> 2.0.CO;2.

Taylor, C. M. (2008), Intraseasonal land-atmosphere coupling in the West African Monsoon, J. Clim., 21, 6636-6648, doi:10.1175/ 2008JCLI2475.1.

Taylor, C. M., and T. Lebel (1998), Observational evidence of persistent convective-scale rainfall patterns, Mon. Weather Rev., 126, 1597-1607, doi:10.1175/1520-0493(1998)126<1597:OEOPCS>2.0.CO;2. 
Timouk, F., L. Kergoat, E. Mougin, C. R. Lloyd, E. Ceschia, J.-M. Cohard, P. de Rosnay, P. Hiernaux, V. Demarez, and C. M. Taylor (2009), Response of surface energy balance to water regime and vegetation development in a Sahelian landscape, J. Hydrol., 375, 178-189, doi:10.1016/j.jhydrol.2009.04.022.

Trenberth, K. E. (1999), Atmospheric moisture recycling: Role of advection and local evaporation, J. Clim., 12, 1368-1381, doi:10.1175/15200442(1999)012<1368:AMRROA>2.0.CO;2.

Trenberth, K. E., and C. J. Guillemot (1995), Evaluation of the global atmospheric moisture budget as seen from analyses, J. Clim., 8, 22552272, doi:10.1175/1520-0442(1995)008<2255:EOTGAM >2.0.CO;2.

Vizy, E. K., and K. H. Cook (2001), Mechanisms by which Gulf of Guinea and eastern North Atlantic sea surface temperature anomalies can influence African rainfall, J. Clim., 14, 795-821, doi:10.1175/15200442(2001)014<0795:MBWGOG >2.0.CO;2.

Willmott, C. J., C. M. Rowe, and Y. Mintz (1985), Climatology of the terrestrial seasonal water cycle, Int. J. Climatol., 5, 589-606, doi:10.1002 joc. 3370050602 .
Zeng, N., J. Neelin, K.-M. Lau, and J. Compton (1999), Enhancement of interdecadal climate variability in the Sahel by vegetation interaction, Science, 286, 1537-1540, doi:10.1126/science.286.5444.1537.

Zhang, C., P. Woodworth, and G. Gu (2006), Seasonal cycle in the lower troposphere over West Africa in sounding observations, Q. J. R. Meteorol. Soc., 132, 2559-2582, doi:10.1256/qj.06.23.

Zheng, X., and E. A. B. Eltahir (1998), The role of vegetation in the dynamics of West African Monsoons, J. Clim., 11, 2078-2096, doi:10.1175/1520-0442(1998)011<2078:TROVIT>2.0.CO;2.

O. Bock and R. Meynadier, LATMOS, Université Pierre et Marie Curie, Tour 45, Couloir 45-46, Boite 102, 4, pl. Jussieu, F-75252 Paris CEDEX 05, France. (olivier.bock@latmos.ipsl.fr)

A. Boone, F. Guichard, and J.-L. Redelsperger, GAME-CNRM, MétéoFrance, 42, ave. Gaspard Coriolis, F-31057 Toulouse CEDEX 01, France. P. Roucou, CRC, Université de Bourgogne, 6 blvd. Gabriel, F-21000 Dijon, France. 